\title{
Research of Single-Particle Compression Ratio and Prediction of Crushed Products and Wear on the 6-DOF Robotic Crusher
}

\author{
Guochen Duan, ${ }^{1}$ Boqiang Shi $\mathbb{D}^{1},{ }^{1}$ and Jie $\mathrm{Gu}^{2}$ \\ ${ }^{1}$ School of Mechanical and Engineering, University of Science \&Technology Beijing, Beijing 100083, China \\ ${ }^{2}$ Beijing Institute of Space Launch Technology, Beijing 100076, China \\ Correspondence should be addressed to Boqiang Shi; shiboqiang@ustb.edu.cn
}

Received 25 October 2020; Revised 7 February 2021; Accepted 18 February 2021; Published 2 March 2021

Academic Editor: Chen Feng Li

Copyright $\left({ }_{0} 2021\right.$ Guochen Duan et al. This is an open access article distributed under the Creative Commons Attribution License, which permits unrestricted use, distribution, and reproduction in any medium, provided the original work is properly cited.

In order to reduce wear and increase crushing efficiency of the 6-DOF (degree of freedom) robotic crusher, the maximum single-particle compression ratio function of the granular material and the wear model of the mantle liner under eccentric compression are established. The function and model take into account the influence of crusher parameters and granular material parameters on maximum single-particle compression ratio, which is simulated by EDEM and obtained under different conditions. Combined with previous research, the theoretical distribution of crushed products and the crushing chamber size can be obtained at each time of the whole life cycle of the liner. Compared with the experimental data of Ansteel Group in previous research, the difference between the functional model and the actual results is small. This function is universal and can be used to provide reference for the 6-DOF robotic crusher's crushing strategy and a theoretical basis and a design reference of the traditional structure cone crusher.

\section{Introduction}

Cone crusher is one of the most widely used crushing equipment in crushing operation. Granular material is crushed into small particles in the crushing chamber by eccentric motion of the mantle. The structure of the traditional cone crusher is shown in Figure 1(a).

The working mode is that spindle 1 drives eccentric sleeve 2, and mantle 3 is driven by eccentric sleeve 2 to achieve eccentric rotation, so the granular material particles in the crushing chamber are extruded. When the mantle extrudes the granular material, the liner will rub with the material, thus causing wear. Because of wear, the shape of the crushing chamber will change, and the particle size of crushed products will deteriorate [1-4]. The main failure mode of the liner is wear. The total economic loss caused by mining friction and wear is estimated to be 2.1 billion euro per year [5], so it is necessary to research the liner wear. There have been a lot of research studies on liner wear. It mainly focuses on the crushing chamber size, structure, working conditions, and wear mechanism. The research methods mainly include experiment and discrete element method (DEM) simulation. Lindqvist and Evertsson [6] established a model to predict the worn geometry of cone crushers. Franke et al. [7] used the DEM to predict wear and profile evolution of liners over the life cycle for specific sets of conditions. Ala-Kleme et al. [8] researched liner materials and compared the wear resistance of different composites. $\mathrm{Li}$ et al. [9] researched the functional relationship of the movement and geometry parameters of the cone crusher and the liner wear using the DEM. Wang et al. [10] researched the microscopic influence of sliding distance and load on the wear of the cone crusher liner. Delaney et al. [11] presented predictions of particle flow and compression breakage of nonround rock passing through an industrial scale cone crusher using the DEM, and by these predictions through the crusher, products' size distribution and liner wear were discussed. André and Tavares [12] used the discrete element model to simulate the crushing of the mixture containing tough and soft components. The results showed that the crusher throughput would not drop proportionally with the increase of the amount of tough materials in the feed. Cleary and Sinnott [13] predicted machine-level operation and estimated crusher wear using the DEM. In addition to the 


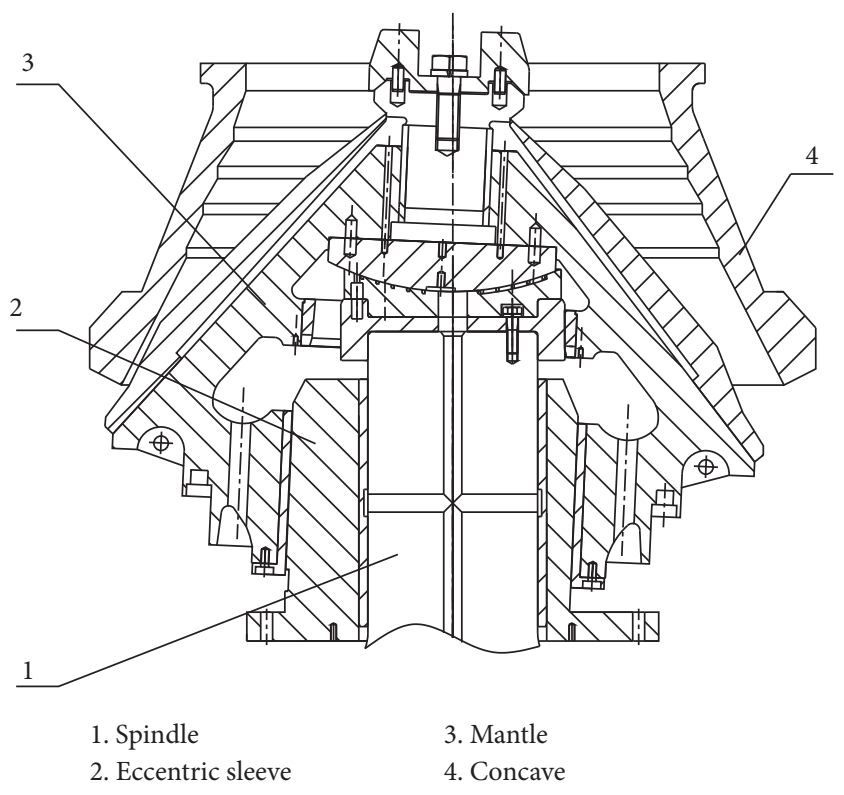

(a)

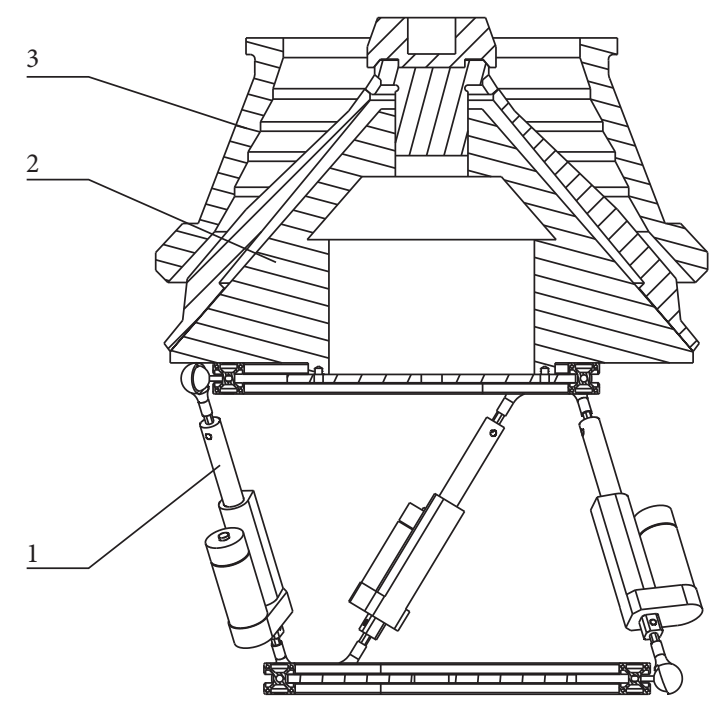

1. Actuator
2. Mantle
3. Concave

Figure 1: Structure of the (a) traditional cone crusher and (b) 6-DOF robotic crusher.

DEM, there are also finite element method (FEM) [14-16] and semianalytical method (SAM) [17-19] to calculate wear. All the above research studies are based on traditional crushing equipment. For the 6-DOF robotic crusher, the corresponding research needs to be carried on.

The structure of the 6-DOF robotic crusher is shown in Figure 1(b) [20]. Mantle 2 is driven by actuator 1 to achieve eccentric compression. Compared with the traditional cone crusher, the biggest difference is that the movement mode of the mantle can be adjusted in real time by adjusting the motion of the actuator. Therefore, how to adjust the motion mode of the mantle, that is, the control strategy of the actuator, will become an important research content. The granular material parameter is an important reference for adjustment. In order to achieve the optimal crushing of materials, the motion mode of the mantle should be adjusted according to the particle size distribution in the crushing chamber. Therefore, it is necessary to research the process and products of material crushing. Previous studies have considered materials as a whole. In the study of single particle $[21,22]$, only single particle or specimen is considered, and the characteristics of the granular material are not considered. Other research studies $[23,24]$ that consider the properties of the granular material do not consider the characteristics of eccentric compression, and the experimental conditions are confining compression. Based on previous research, it is limited to give full play to the advantages of the 6-DOF robotic crusher, that is, to achieve optimal crushing. For single particle, the single-particle compression ratio is closely related to the distribution of crushed products. It is necessary to research the distribution of the maximum single-particle compression ratio under different working conditions. DEM is widely used in the research of crushers as the main method to study the behaviour of particles. EDEM is commercial software, developed by DEM Solutions in Edinburgh, Scotland. It is used to research the interaction between particles, the change of particle size [25], the numerical calculation of kinematics, and dynamics of the granular material [26], and it is applied to the design of the cone crusher [27]. In this paper, the maximum single-particle compression ratio under different conditions is obtained by using EDEM simulation. The maximum single-particle compression ratio and liner wear model are established as a function of expectation of particle size, actual compression ratio of the granular material, original compression thickness, and particle size distribution coefficient. Based on the authors' previous research results [28], the crushed products' distribution and wear in the whole liner life cycle are calculated by the above functions and models, which are universal and can be used as a control strategy basis for real-time regulation of the 6-DOF robotic crusher. It can also provide design reference for cone crusher with traditional structure.

\section{Single-Particle Compression Ratio and Crushed Products' Function}

2.1. Single-Particle Compression Ratio. The particle will deform under the action of forces. In EDEM simulation, the particles are linear elastic particles, and the contact between particles is Hertz contact model. As shown in Figure 2, the deformation of single-particle radius $\Delta R_{\mathrm{P}}$ under the action of normal force $N$ can be obtained when the particles are arranged in order.

The single-particle compression ratio is 

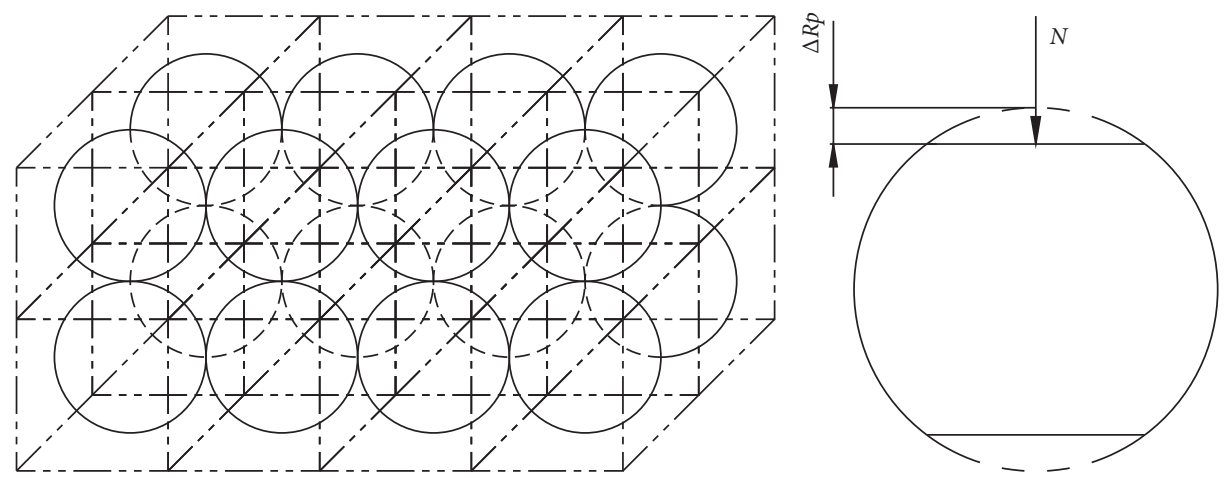

FIgURe 2: Particles' position when the particles are arranged in order and deformation of single-particle radius.

$$
\eta_{s}=\frac{\Delta R_{P}}{R_{P}}
$$

where $R_{p}$ is the single-particle radius.

The functional relationship between $N$ and $\Delta R_{p}$ is

$$
N=\frac{4 E}{3\left(1-v^{2}\right)} R_{P}^{1 / 2} \Delta R_{P}^{3 / 2},
$$

where $E$ is the elastic modulus and $v$ is Poisson's ratio. Then, the functional relationship between single-particle compression ratio $\eta_{\mathrm{s}}$ and normal force $N$ in the elastic phase is

$$
\eta_{s}=\left(\frac{3 N\left(1-v^{2}\right)}{4 E R_{P}^{2}}\right)^{2 / 3}
$$

Granular material is composed of a large number of particles. When it is compressed, the internal particles will slide relatively, so the single-particle compression ratio is different from the actual compression ratio of the granular material, and they obey some probabilistic distributions. In a swing period of the mantle, the single-particle compression ratio of each particle changes with the volume of the crushing chamber caused by the swing of the mantle, and the maximum single-particle compression ratio of each particle in a cycle will determine whether the particle is crushed or not. If the particles are crushed, the maximum single-particle compression ratio will also determine the distribution of crushed products. The distribution of the maximum single-particle compression ratio in a swing period of the mantle is defined as $f_{\eta_{s}}\left(\eta_{s}\right)$. The single-particle compression ratio of each particle will determine the distribution of crushed products. So, it is necessary to establish the model of single-particle crushed products.

2.2. Single-Particle Crushed Products. Taking crushed products of the iron ore as an example, Hertz-Mindlin with the bonding model in EDEM is used to simulate the single-particle crushed products. The particle bonding parameters are set as iron ore: the particle size before replacement was $40 \mathrm{~mm}$; the particle size after replacement is $1.25 \mathrm{~mm}$; normal stiffness per unit area is $2 \mathrm{GPa}$; shear stiffness per unit area is $800 \mathrm{MPa}$; critical normal stress is $19 \mathrm{MPa}$; shear normal stress is $8 \mathrm{MPa}$; and bond disk radius is $0.66 \mathrm{~mm}[29,30]$. When the particle size before replacement changes, the particle size after replacement and bond disk radius change in proportion with the particle size.

The particle size distribution of crushed products can be described by 3-parameter beta distribution in [28], that is, the mass fraction of the ratio of crushed particle size $d_{o}$ and feed particle size $d_{i}$ obeys beta distribution, that is,

$$
\frac{d_{o}}{d_{i}} \sim \operatorname{Be}(\alpha, \beta),
$$

where $\alpha$ and $\beta$ are parameters of beta distribution, which affect the shape and skewness of the beta distribution curve. For determining the crushed particle size $d_{o}, d_{i}$ is introduced to establish the 3-parameter beta distribution. The probability distribution function of beta distribution is

$$
\int_{0}^{x} \frac{\Gamma(\alpha+\beta)}{\Gamma(\alpha) \Gamma(\beta)} t^{\alpha-1}(1-t)^{\beta-1} \mathrm{~d} t, \quad 0<x<1,
$$

where $\Gamma$ is the gamma function and $\Gamma(x)=\int_{0}^{+\infty} t^{x-1} e^{-t} \mathrm{~d} t(x>0)$.

Let $t=d_{o} / d_{i}$; equation (5) is transformed into

$$
\int_{0}^{d_{o}} \frac{1}{d_{i}} \frac{\Gamma(\alpha+\beta)}{\Gamma(\alpha) \Gamma(\beta)}\left(\frac{d_{o}}{d_{i}}\right)^{\alpha-1}\left(1-\frac{d_{o}}{d_{i}}\right)^{\beta-1} \mathrm{~d} d_{o}, \quad 0<d_{o}<d_{i} .
$$

The 3-parameter beta distribution function of crushed products is established.

The expectation of crushed particle size of the 3-parameter beta distribution function is

$$
E_{\mathrm{cp}}=\frac{\alpha}{\alpha+\beta} d_{i}
$$

The variance is

$$
D_{\mathrm{cp}}=\frac{\alpha \beta}{(\alpha+\beta)^{2}(\alpha+\beta+1)} d_{i}^{2} .
$$

Therefore, the particle size distribution of single-particle crushed products can be expressed as 


$$
d_{o} \sim \operatorname{Be}(\alpha, \beta) d_{i}
$$

Combining the distribution model of single-particle crushed products with the distribution of single-particle compression ratio in Section 2.1, the crushed products of the granular material can be obtained.

2.3. Granular Material Crushed Products. The continuous breakage function is established. When the feed particle size $d_{i}$ is the specific value, the probability density function of the single-particle crushed product is expressed by equation (6). When $d_{i}$ is a variable, the probability density function of the single-particle crushed product is a continuous breakage function. Because the distribution of single-particle crushed products is related to the single-particle compression ratio $\eta_{s}$, the continuous breakage function is a function of $d_{i}, d_{o}$, and $\eta_{s}$, that is,

$$
b\left(d_{i}, d_{o}, \eta_{s}\right)=\frac{1}{d_{i}} \frac{\Gamma(\alpha+\beta)}{\Gamma(\alpha) \Gamma(\beta)}\left(\frac{d_{o}}{d_{i}}\right)^{\alpha-1}\left(1-\frac{d_{o}}{d_{i}}\right)^{\beta-1}, \quad 0<d_{o}<d_{i}, d_{i}>0, \eta_{s} \geq \eta_{c}
$$

where $\eta_{c}$ is the critical compression ratio of single-particle crushing.

The probability density function of feed particle size distribution is defined as $f_{d_{i}}\left(d_{i}\right)$. The distribution of the maximum single-particle compression ratio is defined as $f_{\eta_{s}}\left(\eta_{s}\right)$ in Section 2.2. So, the mass fraction of a particle size at a certain compression ratio is $f_{d_{i}}\left(d_{i}\right) f_{\eta_{s}}\left(\eta_{s}\right) \mathrm{d} d_{i} \mathrm{~d} \eta_{s}$. The mass distribution of the crushed products of the particle size and compression ratio is $b\left(d_{i}, d_{o}, \eta_{s}\right) f_{d_{i}}\left(d_{i}\right) f_{\eta_{s}}\left(\eta_{s}\right) \mathrm{d} d_{i} \mathrm{~d} \eta_{s}$. The distribution of granular material crushed products is

$$
f_{d_{o}}\left(d_{o}\right)=\int_{0}^{1} \int_{0}^{d_{i, \max }} b\left(d_{i}, d_{o}, \eta_{s}\right) f_{d_{i}}\left(d_{i}\right) f_{\eta_{s}}\left(\eta_{s}\right) \mathrm{d} d_{i} \mathrm{~d} \eta_{s}
$$

When $\eta_{s} \geq \eta_{c}$, the material can be crushed, and the distribution of crushed products is

$$
f_{d_{o}}\left(d_{o}\right)=\int_{\eta_{c}}^{1} \int_{0}^{d_{i, \max }} b\left(d_{i}, d_{o}, \eta_{s}\right) f_{d_{i}}\left(d_{i}\right) f_{\eta_{s}}\left(\eta_{s}\right) \mathrm{d} d_{i} \mathrm{~d} \eta_{s}
$$

When $\eta_{s}<\eta_{c}$, the material cannot be crushed. In this case, $d_{o}=d_{i}$. The distribution of crushed products is

$$
f_{d_{o}}\left(d_{o}\right)=f_{d_{i}}\left(d_{i}\right) \int_{0}^{\eta_{c}} f_{\eta_{s}}\left(\eta_{s}\right) d \eta_{s}
$$

According to equations (11) and (12), the distribution of the whole granular material crushed product is

$$
f_{d_{o}, c r}\left(d_{o}\right)=\int_{\eta_{c}}^{1} \int_{0}^{d_{i, \max }} b\left(d_{i}, d_{o}, \eta_{s}\right) f_{d_{i}}\left(d_{i}\right) f_{\eta_{s}}\left(\eta_{s}\right) \mathrm{d} d_{i} \mathrm{~d} \eta_{s}+f_{d_{i}}\left(d_{i}\right) \int_{0}^{\eta_{c}} f_{\eta_{s}}\left(\eta_{s}\right) \mathrm{d} \eta_{s} .
$$

\section{Wear Model of the Mantle Liner}

The movement mode of the mantle is shown in Figure 3.

Figure 3(a) shows the axonometric projection of the mantle. The motion of the mantle can be regarded as the composite motion of the $x \mathrm{Oz}$ plane and the $y \mathrm{Oz}$ plane swinging around the suspension point, with a phase difference of $90^{\circ}$. So, each point on the mantle will move in a circle around a fixed centre. The projection of the movement of the mantle on the $x O z$ plane is shown in the side view of Figure 3(b). The contour of the solid line and double dot-dash line is the left and right limit position of the mantle, and the dimension parameters of the crushing chamber are shown in Figure 4.

In Figure 4(a), $b$ is the length of the open side; $c s$ is the length of the closed side. In order to set simulation parameters and calculate volume of the crushing chamber, the original compression thickness $c r$ is introduced. In Figure 4(b), $c r$ is the original compression thickness; $s$ is the stroke on the mantle. Among the above parameters, $b=c r+s$ and $c s=c r-s . \varphi_{p}$ is the precession angle of the mantle. In Figure 4(c), it is specified that the closed side direction of the mantle is the polar axis ( $x$-axis) direction of the polar coordinate of the mantle, and the polar angle of any point $S$ on the mantle is $\theta$. Because of the swing of the mantle, the size of the crushing chamber in the circular direction of the same $z$ coordinate on the mantle is different, so the stress of each point in the circumferential direction is different.

The stress and velocity at a point on the mantle are shown in Figure 5.

$\mathbf{p}$ is the normal stress, and $v$ is the velocity. According to the Archard [31] wear model, the liner wear of a point on mantle $\Delta h$ in a cycle is

$$
\Delta h=\frac{K}{H} \int_{0}^{T}|\mathbf{p}(t)||\mathbf{v}(t)| \sin \angle \mathbf{p} \mathbf{v} \mathrm{d} t
$$

where $K$ is the wear coefficient, $H$ is the Brinell hardness of the material, $t$ is the working time, and $\angle \mathbf{p v}$ is the angle of $\mathbf{p}$ and $\mathbf{v} . \mathbf{p}, \mathbf{v}$ can be expressed as a function of time. According to Zhang's research [30], for Hadfield steel, $K=8.7 \times 10^{-6} \mathrm{~mm}^{2} / \mathrm{N}$, and Brinell hardness $H=200$. The mantle cylinder coordinate system is established. The closed side of the mantle is $\theta=0$. The suspension point is $z=0$. The 


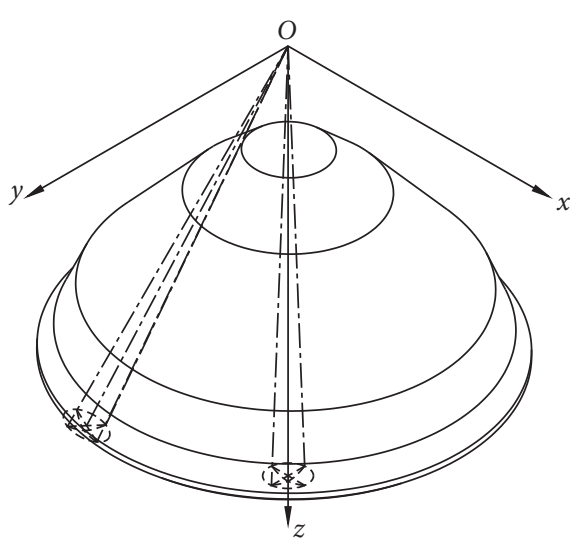

(a)

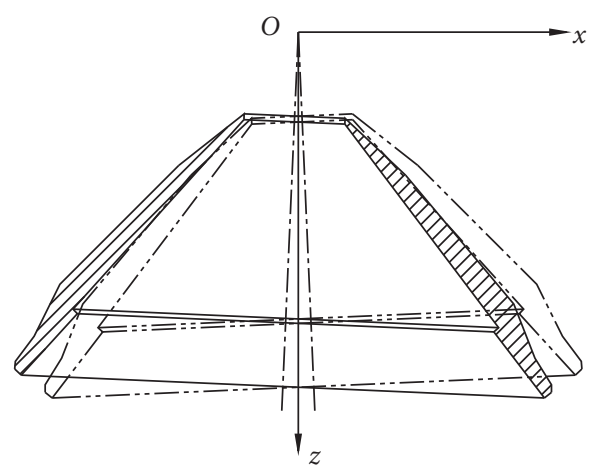

(b)

Figure 3: Movement mode of the mantle. (a) Axonometric projection. (b) Side view.

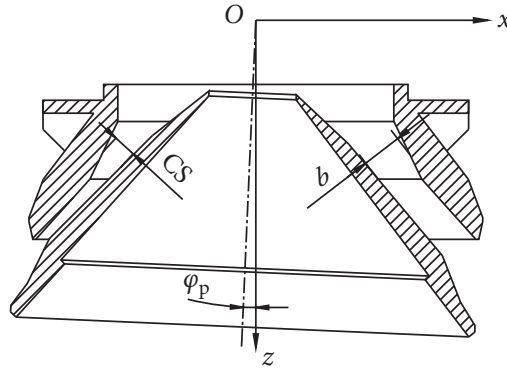

(a)

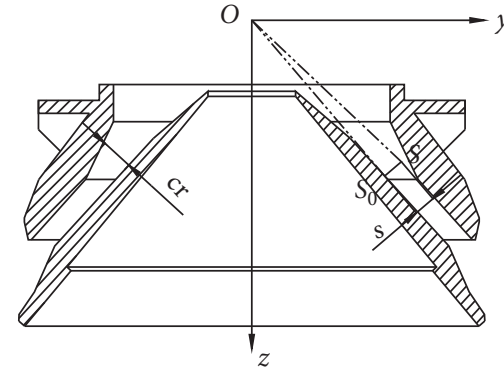

(b)

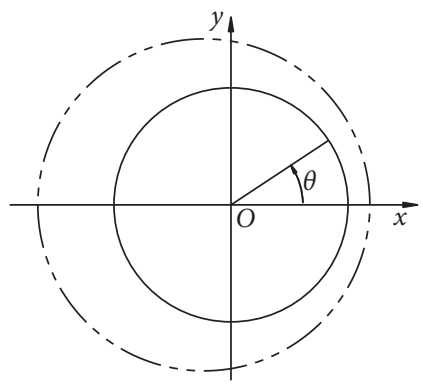

(c)

Figure 4: Dimension parameters of the crushing chamber. (a) Limit position of the mantle. (b) Original position of the mantle. (c) Polar coordinates of the mantle.

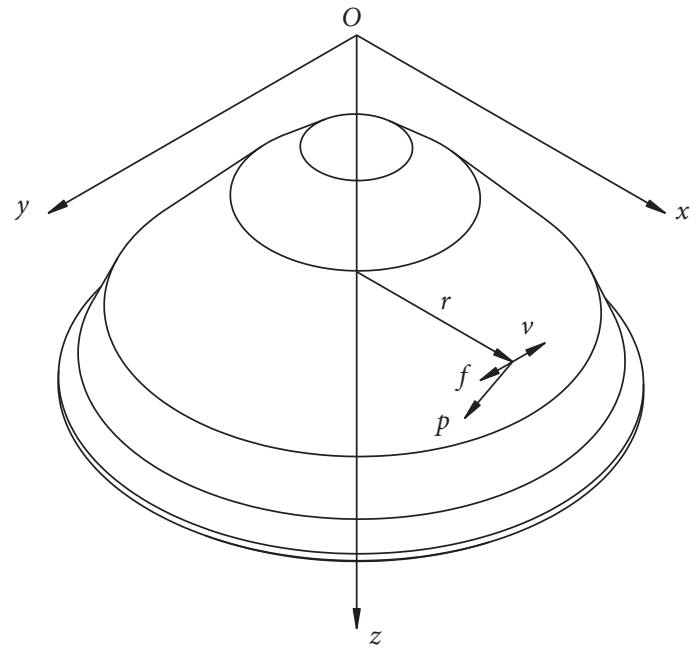

FIGURE 5: Stress and velocity of a point on the mantle. 
stress $\mathbf{p}$ and velocity $\mathbf{v}$ can be expressed as functions of $z$ and $\theta$. With the swing of the mantle, the wear of each point of the same $z$ coordinate on the mantle is the same in a swing period. In a swing period of the mantle, the wear of different $z$ coordinates of the mantle is

$$
\Delta h(z)=\frac{K}{H} \int_{0}^{2 \pi}|\mathbf{p}(\theta, z) \| \mathbf{v}(\theta, z)| \sin \angle \mathbf{p} \mathbf{v} T \mathrm{~d} \theta,
$$

where $T$ is the swing period of the mantle.

According to the previous research [32], the speed of each point on the mantle is

$$
|\mathbf{v}|=R_{O} \omega \sin \varphi_{P}
$$

where $R_{O}$ is the distance between a point on the mantle and the suspension point and $\omega$ is the angular velocity of the mantle. $R_{O}=\sqrt{z^{2}+R_{\mathrm{m}}(z)^{2}}$, and $R_{m}$ is the mantle radius, which is a function of the $z$-coordinate. The angle of $\mathbf{p}$ and $\mathbf{v}$ $\angle \mathbf{p v}$ is

$$
\angle \mathbf{p} \mathbf{v}=\arccos \left(\cos \left(\alpha-\arctan \frac{R_{m}(z)}{z}+\varphi_{P}\right) \cos \left(\theta+\frac{\pi}{2}\right)\right) .
$$

In conclusion, $\mathbf{v}, \angle \mathbf{p v}$ can be expressed by the analytical formula. $\mathbf{p}$ can be determined by simulation.

\section{Simulation Analysis}

4.1. Maximum Single-Particle Compression Ratio Function. For determining the expectation and variance of the maximum single-particle compression ratio distribution defined in Section 2.1, EDEM is used to simulate. The EDEM simulation condition is shown in Figure 6.

The motion mode of the mantle is simple harmonic vibration in $x$ - and $y$-directions but in phase quadrature. Its synthetic motion is eccentric rotation with a certain eccentricity. In EDEM simulation, the interaction of particle to particle is set as Hertz-Mindlin (no slip). The particle parameters are set according to the iron ore. According to Zhang and Brosh et al. [33, 34], Poisson's ratio is 0.2 , the shear modulus is $30 \mathrm{GPa}$, and the critical stress of compression crushing is $200 \mathrm{Mpa}$. According to equation (3), the corresponding critical compression ratio of single-particle crushing $\eta_{c}$ is 0.0153 . The liner of the mantle and concave parameters are set according to Hadfield steel. Poisson's ratio is 0.3 ; the shear modulus is $80 \mathrm{GPa}$. The coefficient of restitution, static fraction, and rolling fraction of the ore are $0.5,0.9$, and 0.05 , respectively. The above three parameters of ore and steel are $0.5,0.5$, and 0.01 , respectively. According to the experimental results, the density of the iron ore is $2719 \mathrm{~kg} / \mathrm{m}^{3}$; the density of Hadfield steel is $7768 \mathrm{~kg} / \mathrm{m}^{3}$.

The basic conditions are as follows: rotational speed $n_{\text {basic }}=300 \mathrm{rpm}$, material height $h_{\text {basic }}=150 \mathrm{~mm}$, mantle diameter $D_{m}$, basic $=1080 \mathrm{~mm}$, actual compression ratio of the granular material $\eta_{\text {a,basic }}=0.25$, and original compression thickness $c r_{\text {basic }}=110 \mathrm{~mm}$. The particle size is $28 \mathrm{~mm}$, which can be regarded as the distribution of expectation of particle size $E_{d \text {, basic }}=28 \mathrm{~mm}$ and variance of particle size $D_{d}$, basic $=0 \mathrm{~mm}^{2}$. Under this condition, the maximum singleparticle compression ratio frequency of each particle in a cycle is shown in Figure 7(b).

In Figure $7(\mathrm{~b})$, the expectation of maximum single-particle compression ratio $E_{\text {basic }}=7.147 \times 10^{-2}$, and the variance of maximum single-particle compression ratio $D_{\text {basic }}=6.473 \times 10^{-4}$. In the following simulation, control variates are used to simulate when only one of the six variables in the basic condition is changed. Taking the change of original compression thickness $\mathrm{cr}$ as an example, under different $\mathrm{cr}$, the maximum single-particle compression ratio frequency of each particle in a cycle is shown in Figure 7, which can be described by lognormal distribution. The simulation results show that when the expectation of particle size $E_{d}$ approaches 0 or original compression thickness $\mathrm{cr}$ approaches infinity, the expectation and variance of the maximum single-particle compression ratio $E_{\text {act }}$ and $D_{\text {act }}$ will approach 0 . When actual compression ratio of granular material $\eta_{\mathrm{a}}$ changes, $E_{\text {act }}$ will increase with the increase of $\eta_{\mathrm{a}}$, but the change of $D_{\text {act }}$ ratio is not obvious. When rotational speed $n$, material height $h$, and mantle diameter $D_{\mathrm{m}}$ change, $E_{\text {act }}$ and $D_{\text {act }}$ will not change significantly. Therefore, the function is established as $E_{\text {act }}\left(E_{d}\right.$, $\left.\eta_{\mathrm{a}}, c r\right), D_{\mathrm{act}}\left(E_{d}, \eta_{\mathrm{a}}, c r\right)$. For eliminating the influence of the order of magnitude and dimension, the relative value of each variable is introduced. Let $E_{\text {re }}=E_{\text {act }} / E_{\text {basic }}, D_{\text {re }}=D_{\text {act }} / D_{\text {basic }}$, $E_{d \text {,re }}=E_{d} / E_{d \text {,basic }}$, and $c r_{\text {re }}=c r / c r_{\text {basic }}$, where $E_{\text {act }}$ and $D_{\text {act }}$ are the actual value of expectation and variance under each simulation condition. After simulating, the functional relationship of $E_{\text {re }}, D_{\text {re }}$ and $E_{d \text {,re }}, \eta_{\mathrm{a}}, c r_{\text {re }}$ is shown in Figures 8 and 9.

$E_{\text {act }}$ can be expressed as a power function with $E_{d}, \eta_{\mathrm{a}}, \mathrm{cr}$, and $D_{\text {act }}$ can be expressed as a power function with $E_{d}, c r$.

When the expectation of particle size is constant but the variance changes, for eliminating the dimensional effect, the size distribution coefficient $\sigma_{d}$ is introduced. $\sigma_{d}=D_{d}^{1 / 2} / E_{d}$, where $D_{d}$ is the variance of particle size. The functional relationship between $E_{\mathrm{re}}, D_{\mathrm{re}}$, and $\sigma_{d}$ is shown in Figure 10.

For particles with a specific size in the granular material, the expectation and variance of maximum single-particle compression ratio and the particle size and size distribution coefficient are shown in Figure 11.

$E_{\text {part }}$ and $D_{\text {part }}$ are the expectation and variance of maximum single-particle compression ratio of particles with a specific size, respectively. $d$ is the particle size. $E_{\text {part }}$ and $D_{\text {part }}$ changed little with $d$. So, they can be regarded as unchanged with $d$, that is, $E_{\text {part }}=E_{\text {act }}$ and $D_{\text {part }}=D_{\text {act }}$.

Based on the results of Figures 8-11, the expectation and variance of maximum single-particle compression ratio of particles with a specific size in the granular material can be expressed as 


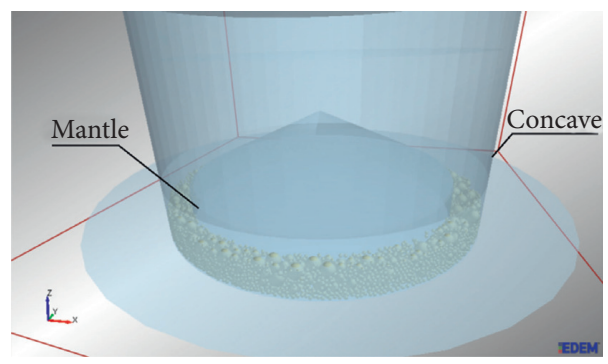

Figure 6: EDEM simulation condition.

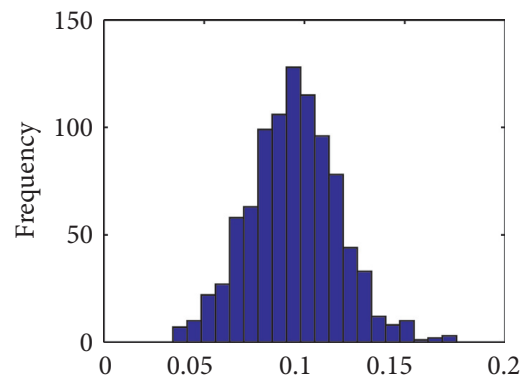

Maximum single-particle compression ratio

(a)

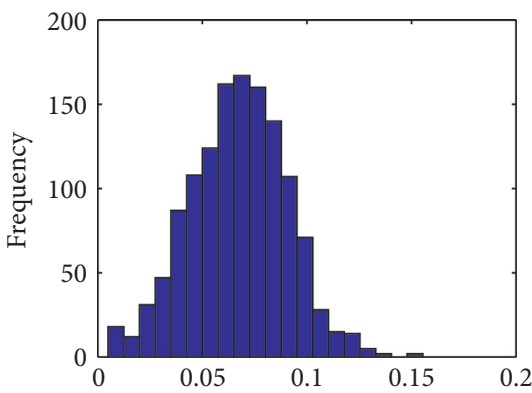

Single-particle compression ratio

(b)

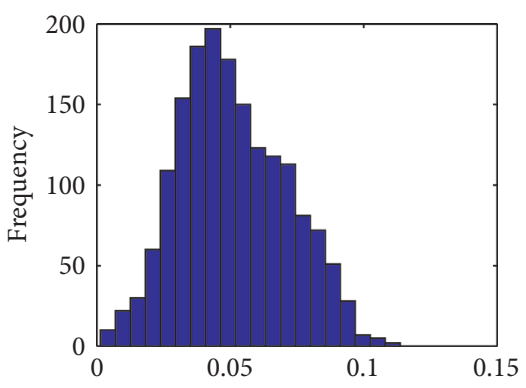

Maximum single-particle compression ratio

(c)

Figure 7: Maximum single-particle compression ratio frequency of each particle under different original compression thicknesses. (a) $c r=80 \mathrm{~mm}$. (b) $c r=110 \mathrm{~mm}$. (c) $c r=140 \mathrm{~mm}$.

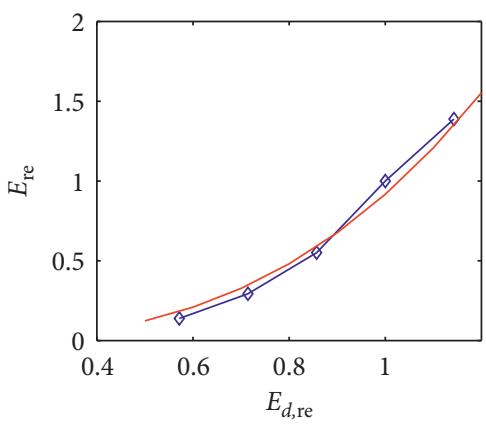

— Actual value

- Fitting value

(a)

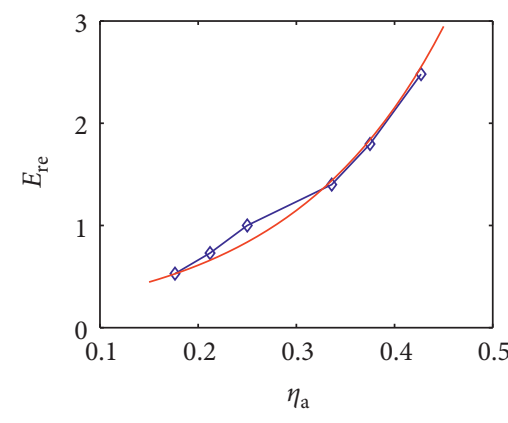

- Actual value

_ Fitting value

(b)

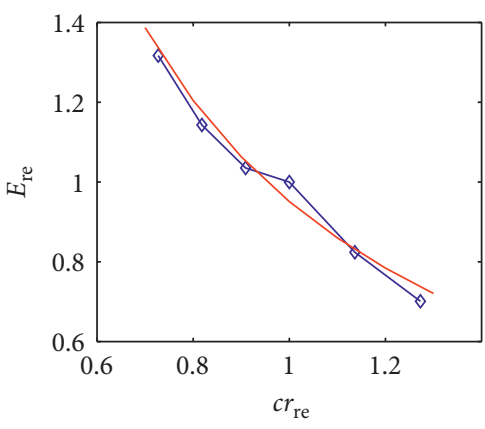

- Actual value

— Fitting value

(c)

Figure 8: Functional relationship of $E_{\mathrm{re}}$ and $E_{d, r e}, \eta_{\mathrm{a}}, c r_{\mathrm{re}}$. (a) $E_{\mathrm{re}}$ and $E_{d, \mathrm{re}}$. (b) $E_{\mathrm{re}}$ and $\eta_{\mathrm{a}}$. (c) $E_{\mathrm{re}}$ and $c r_{\mathrm{re}}$.

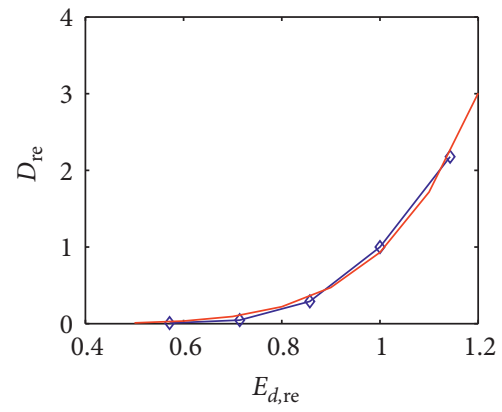

- Actual value - Fitting value

(a)

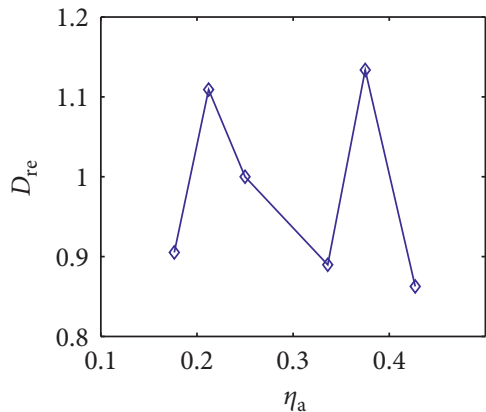

_ Actual value

(b)

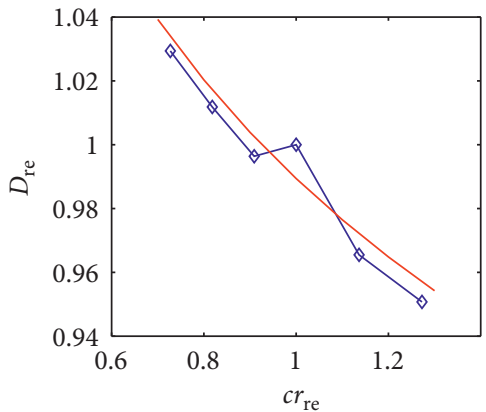

- Actual value

_ Fitting value

(c)

Figure 9: Functional relationship of $D_{\text {re }}$ and $E_{d, r e}, \eta_{\mathrm{a}}, c r_{\text {ree }}$ (a) $D_{\text {re }}$ and $E_{d, \text { ree }}$ (b) $D_{\text {re }}$ and $\eta_{\mathrm{a}}$. (c) $D_{\text {re }}$ and $c r_{\text {re. }}$. 


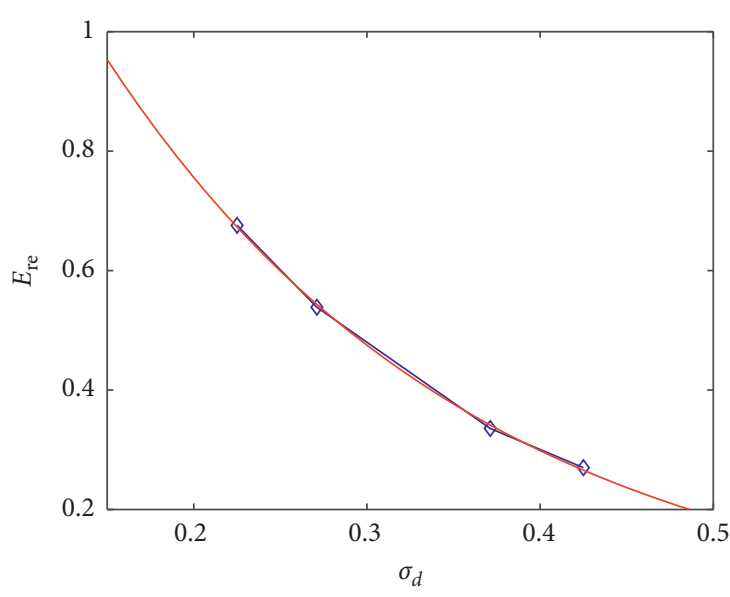

- Actual value

__ Fitting value

(a)

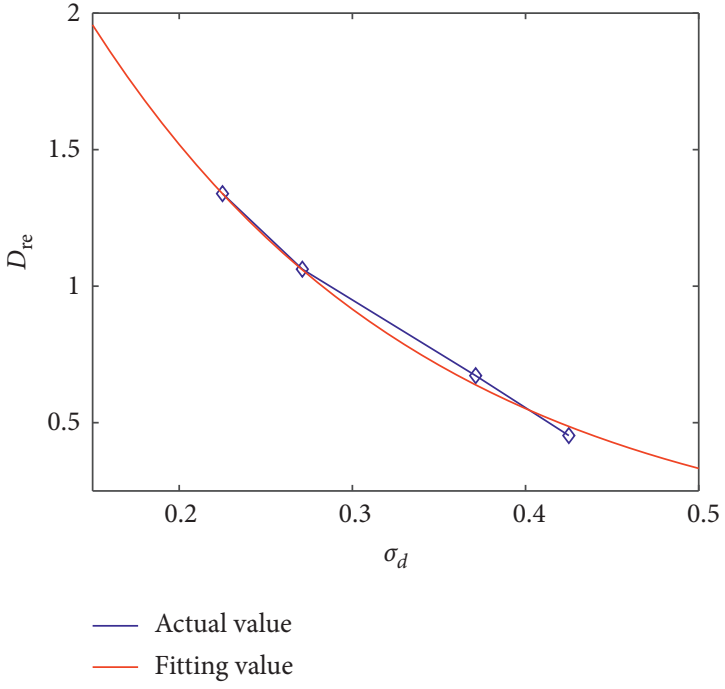

(b)

Figure 10: Functional relationship between $E_{\mathrm{re}}, D_{\mathrm{re}}$, and $\sigma_{d}$. (a) $E_{\mathrm{re}}$ and $\sigma_{d}$. (b) $D_{\mathrm{re}}$ and $\sigma_{d}$.

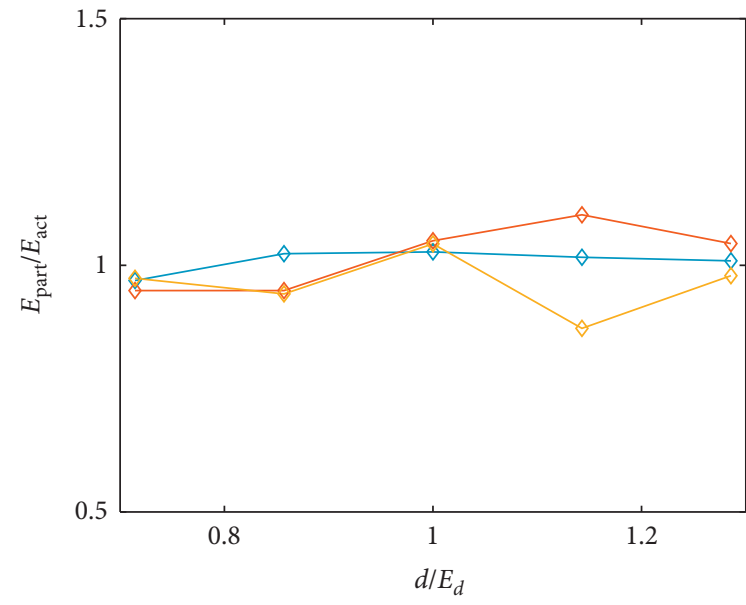
$\triangle \sigma_{d}=0.2020$
$\diamond \sigma_{d}=0.1750$
$\diamond \sigma_{d}=0.1429$

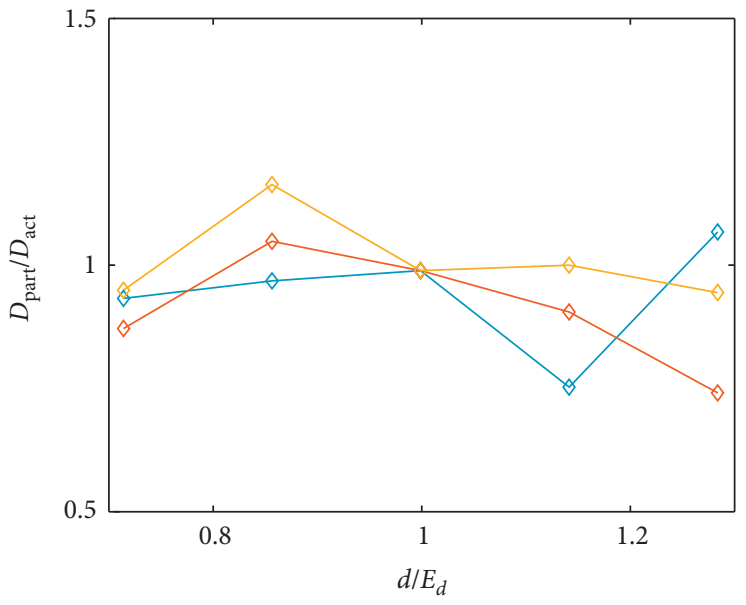
$\diamond \sigma_{d}=0.2020$
$\diamond \sigma_{d}=0.1750$
$\diamond \sigma_{d}=0.1429$

(b)

FIgURE 11: (a) Expectation and (b) variance of maximum single-particle compression ratio of particles with a specific size.

$$
\begin{gathered}
E_{\text {part }}=18.02 E_{\text {basic }} E_{d, \text { re }}^{2.889} \eta_{a}^{1.769} c r_{\text {re }}^{-1.058} \exp \left(-4.643 \sigma_{d}\right), \\
D_{\text {part }}=3.847 D_{\text {basic }} E_{d, \text { re }}^{6.434} c r_{\text {re }}^{-0.1379} \exp \left(-5.063 \sigma_{d}\right) .
\end{gathered}
$$

In conclusion, the maximum single-particle compression ratio of each size particle under certain working conditions can be determined.
4.2. Crushed Products' Function. When the single-particle compression ratio is greater than the critical compression ratio of single-particle crushing $\eta_{c}$, the particle will be crushed. The particle compression crushing process simulated by EDEM is shown in Figure 12.

As shown in Figure 12, the particle size of crushed products is different under different single-particle compression ratios. For single particle, the distribution of 

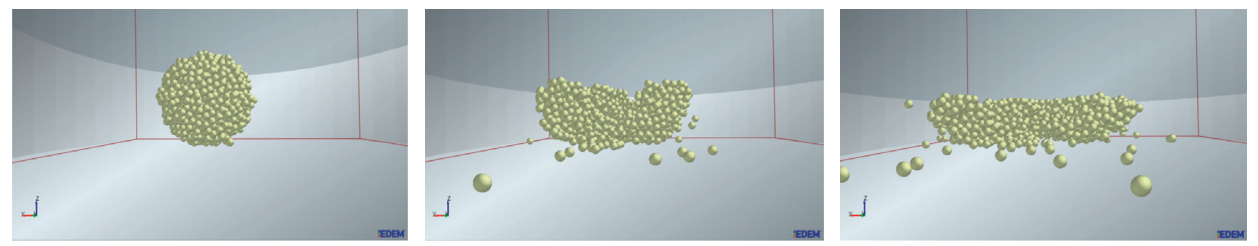

FIgURE 12: Particle compression crushing process.

crushed products can be expressed as a function of the single-particle compression ratio $\eta_{s}$. EDEM is used to simulate the distribution of crushed products under different single-particle compression ratios, and the parameters are set according to Section 2.2. After EDEM simulation, the expectation of crushed products is proportional to the particle size, and the variance is proportional to the square of the particle size. The expectation and variance of particle size of iron ore crushed products under different single-particle compression ratios are shown in Figure 13.

After fitting, expectation and variance of particle size of iron ore crushed products can be expressed as

$$
\begin{aligned}
& E_{\text {cp }}\left(d_{i}, \eta_{s}\right)=\left(-2.675 \eta_{s}^{3}+3.088 \eta_{s}^{2}-1.587 \eta_{s}+0.5851\right) d_{i}, \\
& D_{\text {cp }}\left(d_{i}, \eta_{s}\right)=\left(-0.2625 \eta_{s}^{3}+0.3069 \eta_{s}^{2}-0.1368 \eta_{s}+0.03815\right) d_{i}^{2}
\end{aligned}
$$

According to equations (7a), (7b), (19a), and (19b), the parameters $\alpha$ and $\beta$ can be determined. Therefore, the crushed products of each size particle under different singleparticle compression ratios $\eta_{\mathrm{s}}$ can be determined. Combined with equation (13), the crushing product of the material under certain working conditions can be determined.
4.3. Normal Stress Function. Under the same simulation conditions as in Section 4.1, that is, EDEM simulation with control variates, the normal stress function can be established. The normal stress of the mantle can be expressed by a function of the expectation of particle size $E_{d}$, actual compression ratio of granular material $\eta_{\mathrm{a}}$, original compression thickness $c r$, and size distribution coefficient $\sigma_{d}[32]$, that is,

$$
p=0.2007 \exp \left(1.206 E_{d, \mathrm{re}}+3.998 \eta_{a}-0.5944 c r_{\mathrm{re}}\right)\left(0.2257 \exp \left(-8.521 \sigma_{d}\right)+0.7743\right) p_{\text {basic }}
$$

where $p_{\text {basic }}=0.7102 \mathrm{MPa}$, which is the normal stress under basic conditions in Section 4.1.

On the same $z$-coordinate, the stress distribution on the circumference is

$$
p_{\theta}(\theta)=a \exp (-a \theta) p_{\text {basic }}
$$

where the parameter $a$ is a function of the actual compression ratio of granular material $\eta_{\mathrm{a}}$, and $a=1093 \exp \left(-30.44 \eta_{a}\right)+6.354$.

Combined with equations (14)-(17), the liner wear can be obtained.

\section{Experimental Verification}

5.1. Experimental Conditions and Data. The experimental data of the PYGB1821 cone crusher of Ansteel Group were used to verify. When the PYGB1821 cone crusher works, the rotational speed of the mantle is $300 \mathrm{rpm}$. The crushing process of the granular material in the crushing chamber is shown in Figure 14.
After being compressed and crushed in one crushing layer, the granular material enters the next crushing layer. According to previous research [33], when rotational speed of the mantle is $300 \mathrm{rpm}$, after 10 times of crushing, the material is discharged. Therefore, there are 11 crushing layers. When the crusher is working, the liner will be worn. To ensure the length of the closed side and actual compression ratio of the granular material, the height of concave should be adjusted in an adjustment period. According to Sections 2 and 3, when the working parameters, dimension parameters of the crushing chamber, and material parameters are determined, the crushed products and wear in an adjustment period can be obtained. So, crushed products, wear, and dimension parameters of the crushing chamber in each adjustment period of the whole liner life cycle can be obtained. The calculation flow is shown in Figures 15-17.

Experimental data of feed and output size distribution are shown in Table 1.

The theoretical dimension parameters of the crushing chamber at different working times in the whole liner life cycle are shown in Figure 18. 


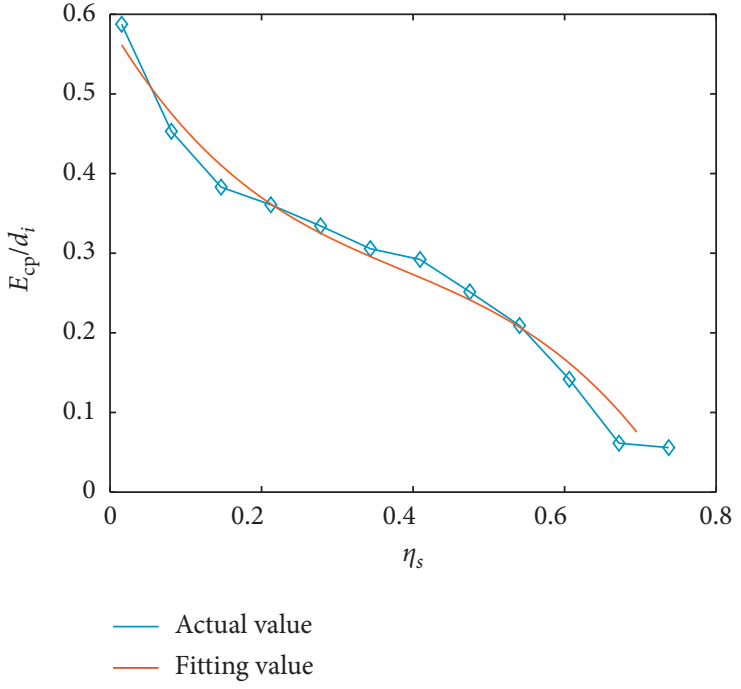

(a)

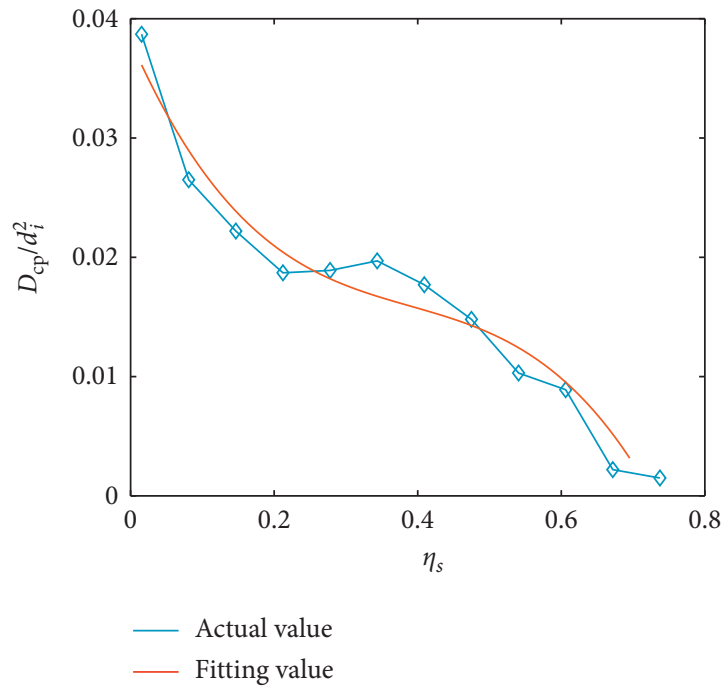

(b)

Figure 13: (a) Expectation and (b) variance of iron ore crushed products.

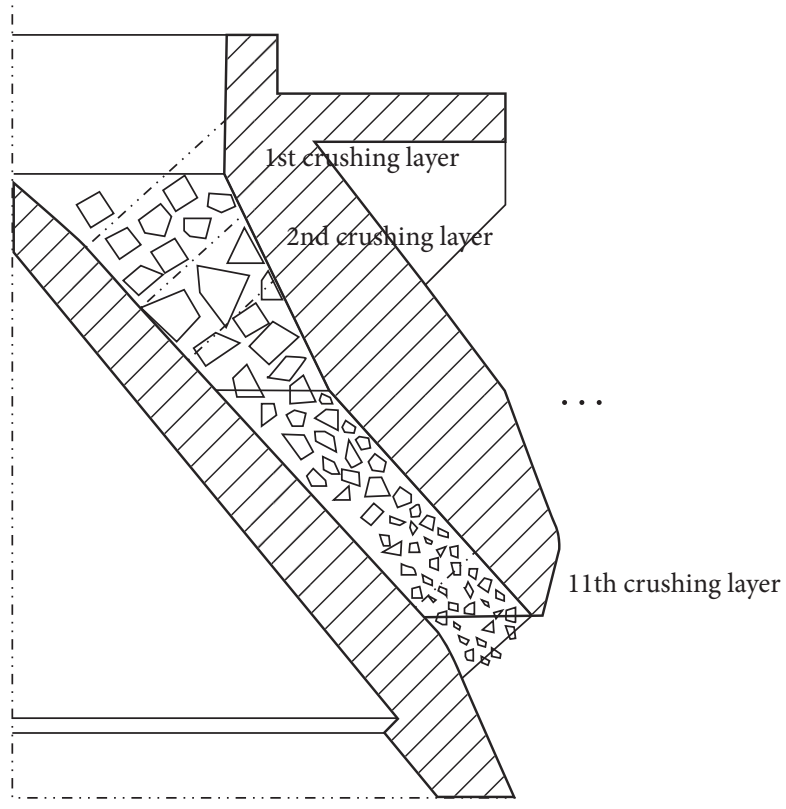

FIGURE 14: Crushing process of the granular material.

The data at 0th hour are the dimension parameters of the crushing chamber when the liner was not worn. Using this data combined with the data in Table 1 , the theoretical dimension parameters in Figure 18 and other theoretical parameters in Figures 19-23 at each time can be obtained according to the flowchart in Figures 15-17. In Figure 15, the maximum height adjustment of concave of the PYGB1821 cone crusher $\Delta z_{\max }=74 \mathrm{~mm}$. When the crusher works for 30,60 , and $90 \mathrm{~h}$, the height adjustment of concave does not reach the maximum. So, in Figure 18(c), the length of the closed side of the parallel zone can be ensured to be close to $19 \mathrm{~mm}$. The parallel zone is the zone with the depth of the crushing chamber from 309 to $521 \mathrm{~mm}$ in Figure 18. The size of other heights of the crushing chamber changes slightly.
When the crusher works for 120 hours, the height adjustment of concave has reached the maximum, and the length of the closed side of the parallel zone changes obviously, which leads to the deterioration of the distribution of crushed products.

The theoretical and experimental mass fraction of crushed products below $7 \mathrm{~mm}, 12 \mathrm{~mm}$, and $24 \mathrm{~mm}$ at different working times are shown in Figure 19.

The diamond symbols in Figure 19 show the experimental data of mass fraction of crushed products below $7 \mathrm{~mm}, 12 \mathrm{~mm}$, and $24 \mathrm{~mm}$ at 35th hour, 100th hour, and 120th hour.

In terms of dimension parameters, the dimension parameters of the crushing chamber can be ensured by 


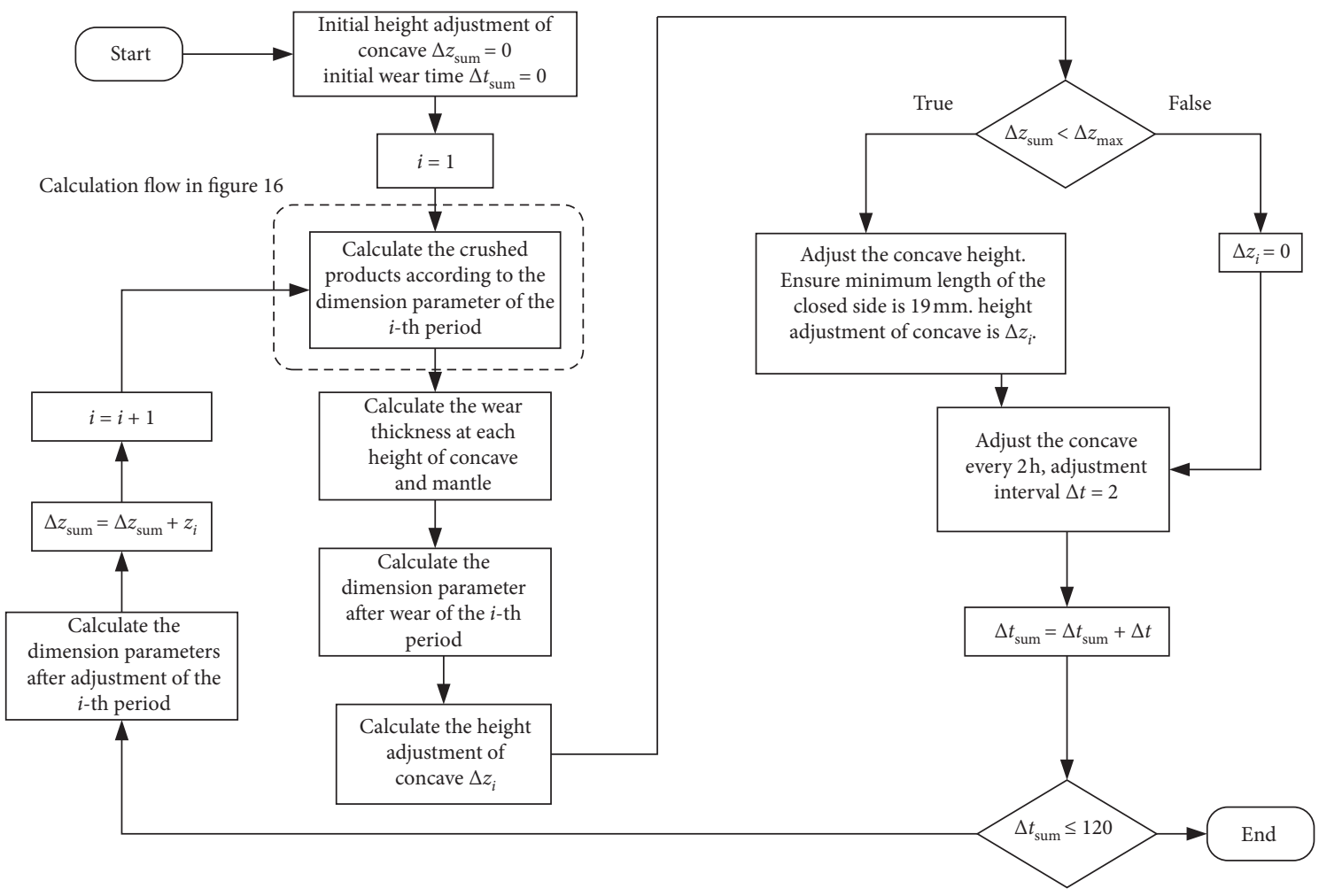

FIgURE 15: Calculation flow of crushed products and wear in the whole liner life cycle.

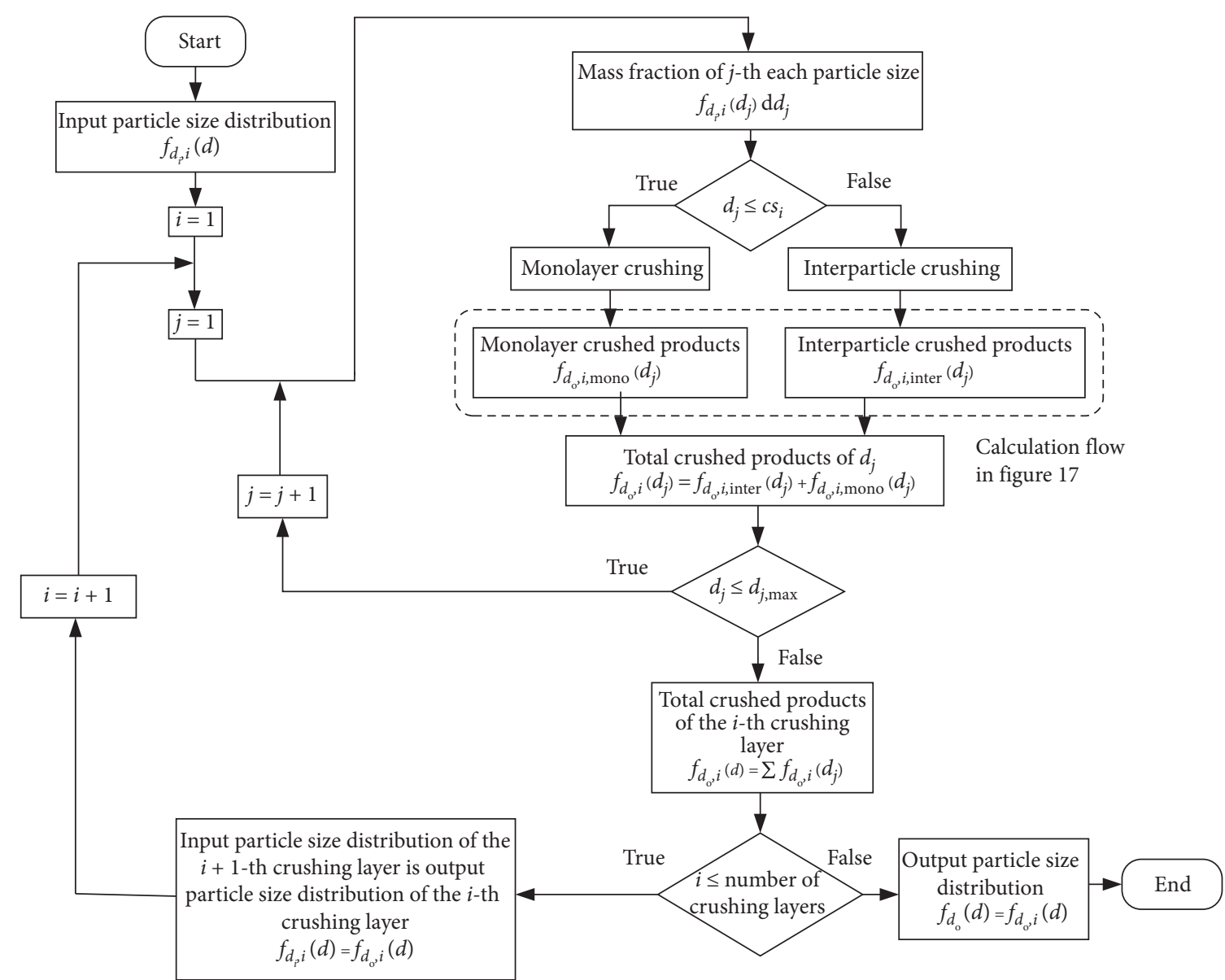

FIGURE 16: Calculation flow of crushed products' distribution. 
Interparticle crushing

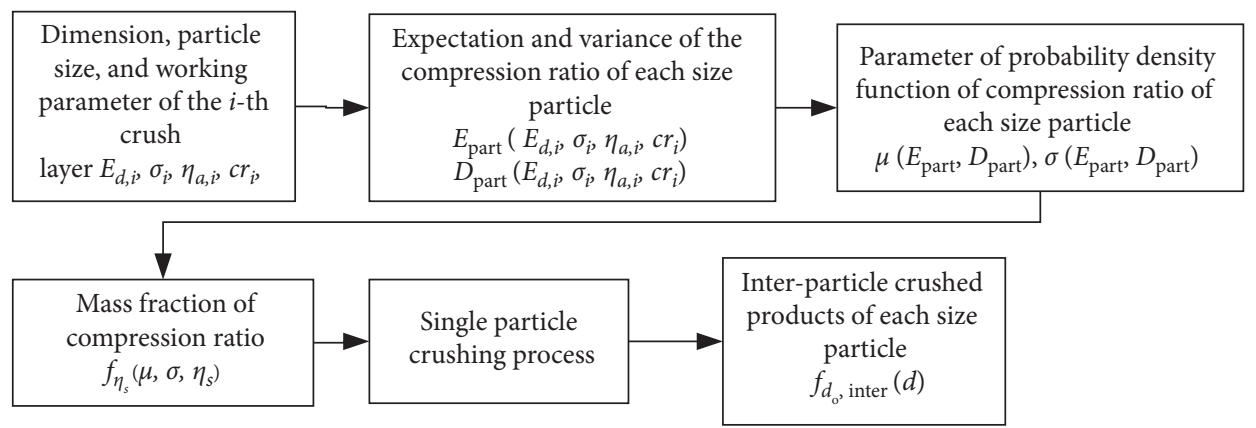

Monolayer crushing

\begin{tabular}{|c|c|c|}
\hline $\begin{array}{c}\text { Single-particle } \\
\text { compression ratio } \\
\eta_{s}=\left(d_{j}-c s\right) / d_{j}\end{array}$ & $\rightarrow \begin{array}{c}\text { Single particle } \\
\text { crushing process }\end{array} \rightarrow \begin{array}{c}\text { Monolayer crushed products } \\
\text { of each size particle } \\
f_{d_{\mathrm{o}}} \text { mono }\end{array}$ \\
\hline
\end{tabular}

Single particle crushing process

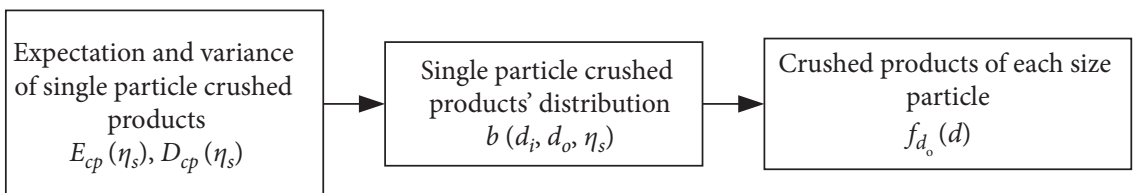

FIGURE 17: Calculation flow of interparticle and monolayer crushed products.

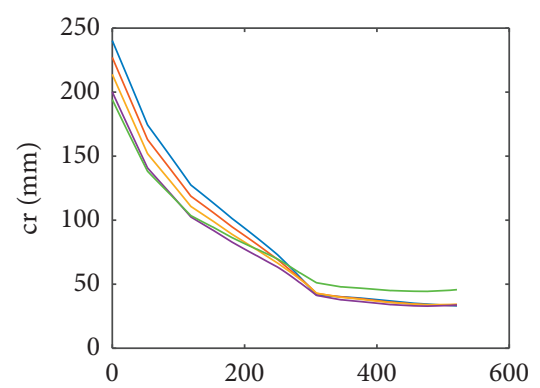

Depth of the crushing chamber $(\mathrm{mm})$

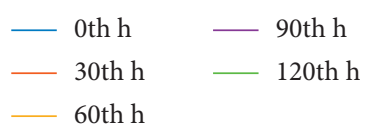

(a)

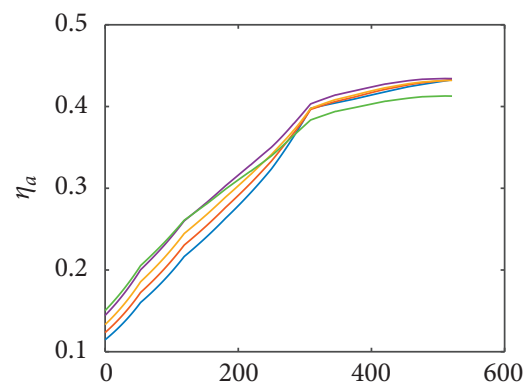

Depth of the crushing chamber (mm)

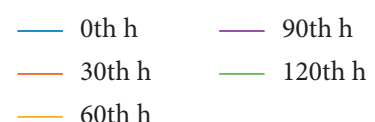

(b)

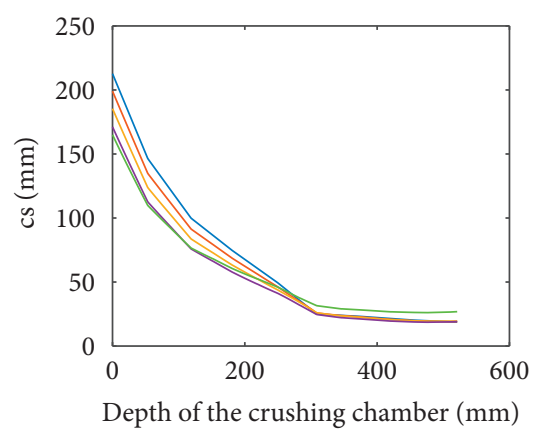

$\begin{array}{ll}\text { - 0th h } & \text { - 90th h } \\ \text { 30th h } & \text { 120th h } \\ \text { 60th h } & \end{array}$

(c)

FIgURE 18: Theoretical dimension parameters of the crushing chamber at different working times in the whole liner life cycle. (a) Original compression thickness. (b) Actual compression ratio of the granular material. (c) Length of the closed side.

TABLE 1: Feed and output size distribution.

\begin{tabular}{|c|c|c|c|c|c|c|}
\hline \multirow{2}{*}{ Particle size $(\mathrm{mm})$} & \multicolumn{2}{|c|}{$35 \mathrm{~h}$} & \multicolumn{2}{|c|}{$100 \mathrm{~h}$} & \multicolumn{2}{|c|}{$120 \mathrm{~h}$} \\
\hline & Feed size (\%) & Output size (\%) & Feed size (\%) & Output size (\%) & Feed size (\%) & Output size (\%) \\
\hline+100 & 2.51 & - & 4.13 & - & 1.87 & - \\
\hline$-100 \sim+66$ & 8.69 & - & 13.25 & - & 12.05 & - \\
\hline$-66 \sim+42$ & 19.42 & - & 16.73 & - & 22.03 & - \\
\hline$-42 \sim+30$ & 19.39 & 1.61 & 18.34 & 2.27 & 17.92 & 2.06 \\
\hline$-30 \sim+24$ & 15.13 & 2.35 & 12.72 & 4.26 & 11.35 & 14.29 \\
\hline$-24 \sim+12$ & 30.31 & 41.29 & 32.17 & 39.54 & 30.77 & 38.45 \\
\hline$-12 \sim+7$ & 3.34 & 23.41 & 1.97 & 20.48 & 3.52 & 17.52 \\
\hline$-7 \sim+5$ & 0.27 & 6.56 & 0.13 & 6.45 & 0.29 & 5.23 \\
\hline$-5 \sim+0$ & 0.94 & 24.78 & 0.56 & 27.00 & 0.20 & 22.45 \\
\hline Particle size distribution coefficient & 0.61 & 0.63 & 0.63 & 0.62 & 0.60 & 0.67 \\
\hline
\end{tabular}




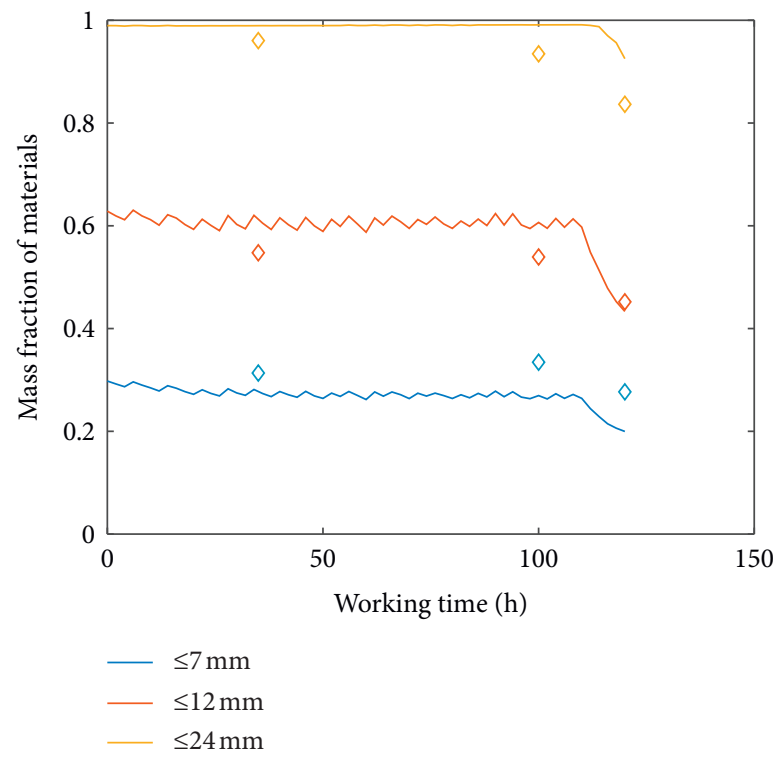

FIgURE 19: Theoretical and experimental mass fraction of crushed products below $7 \mathrm{~mm}, 12 \mathrm{~mm}$, and $24 \mathrm{~mm}$ at different working times.

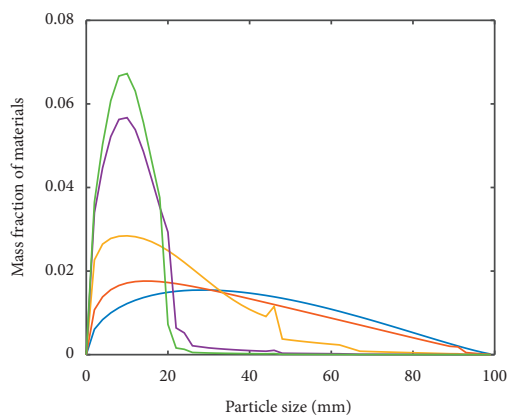

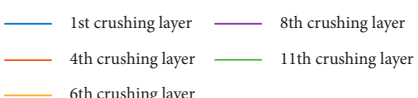

(a)
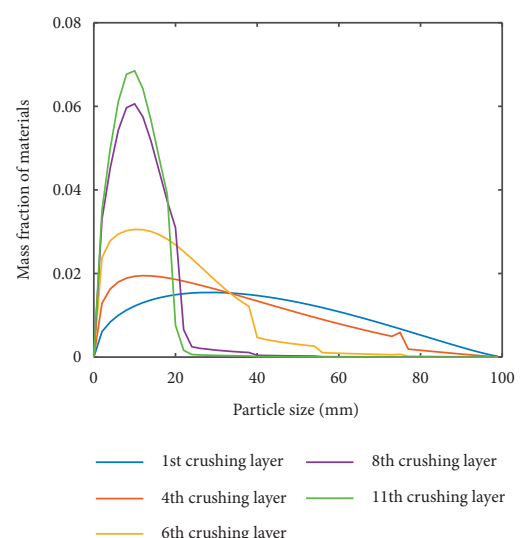

(b)
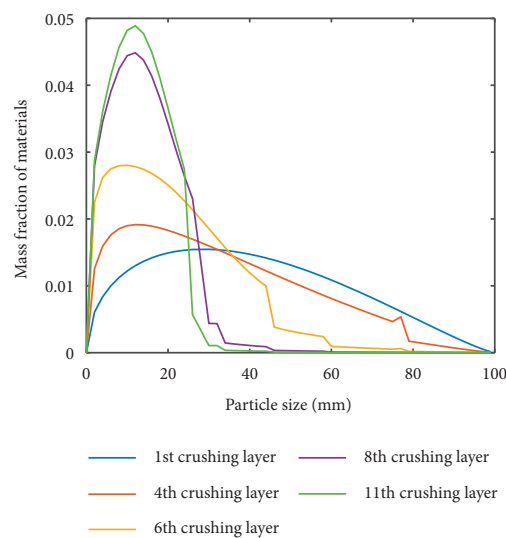

(c)

Figure 20: Theoretical distribution of crushed products in different crushing layers. (a) 35th hour. (b) 100th hour. (c) 120th hour.

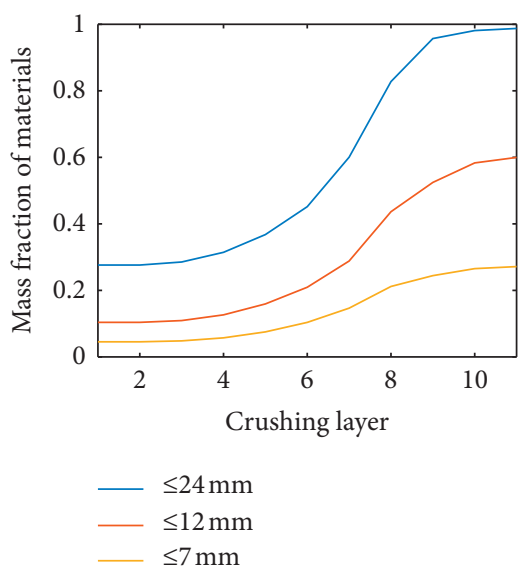

(a)

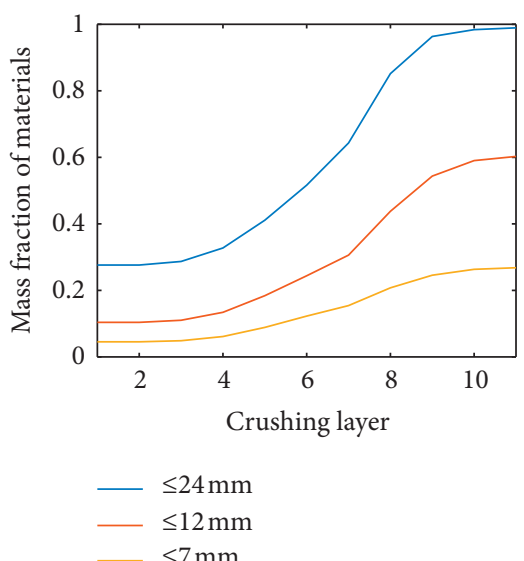

(b)

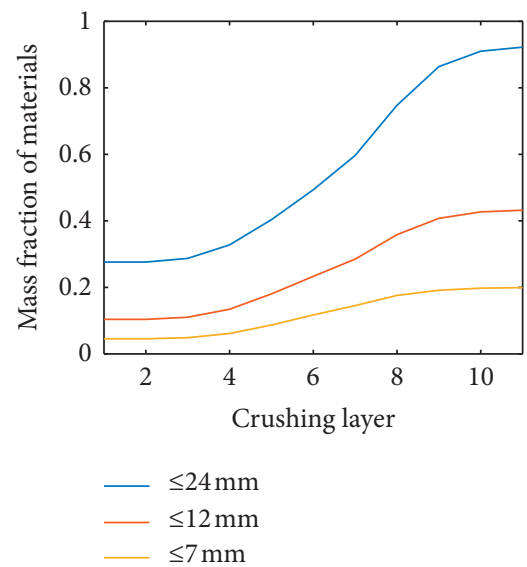

(c)

FIGURE 21: Theoretical mass fraction of crushed products changing in each crushing layer. (a) 35th hour. (b) 100th hour. (c) 120th hour. 


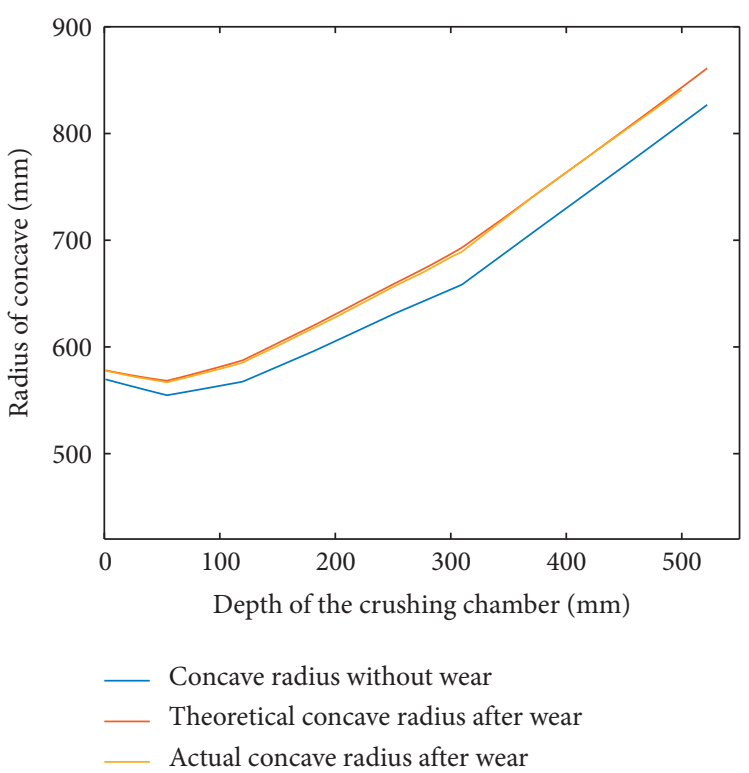

(a)

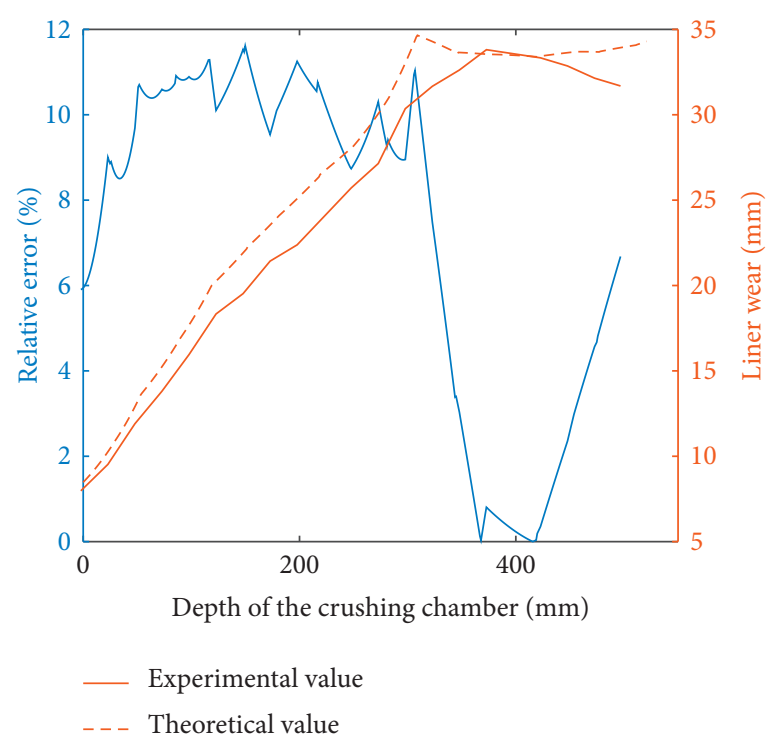

(b)

Figure 22: (a) Concave profile before and after wear and liner wear at 120th hour. (b) Theoretical and experimental values of wear and relative error of wear.

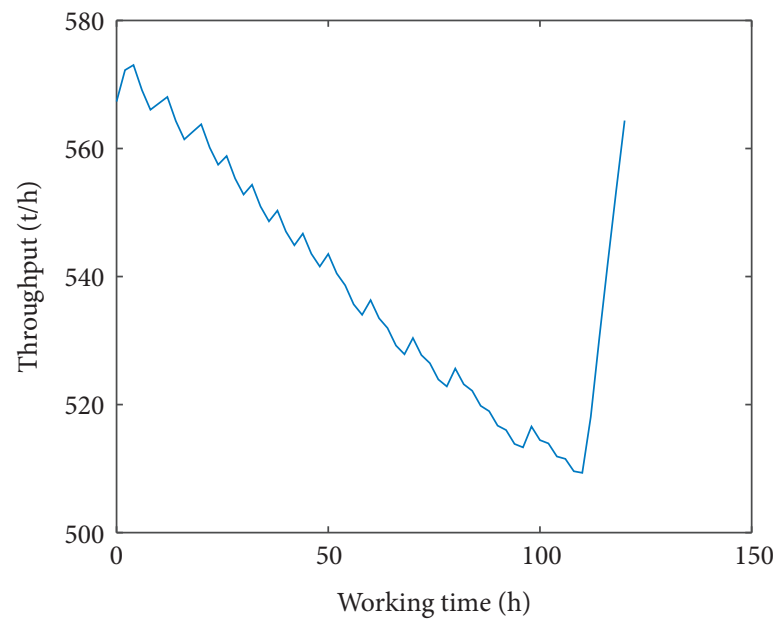

FIgURE 23: Theoretical throughput at different working times.

adjusting the height of concave before 110th hour. So, the particle size of the products is fine. After 110th hour, the adjustment amount of concave reaches the maximum, which cannot guarantee the original compression thickness and actual compression ratio of the granular material. As a result, the size of the crushed products deteriorates. In terms of material parameters, compared with the experimental data, the error of mass fraction of particle size below $7 \mathrm{~mm}$, $12 \mathrm{~mm}$, and $24 \mathrm{~mm}$ is $3.99 \%, 5.77 \%$, and $2.91 \%$ at 35 th hour, $6.59 \%, 5.72 \%$, and $5.63 \%$ at 100 th hour, and $7.71 \%, 1.87 \%$, and $8.87 \%$ at 120 th hour, respectively.

The theoretical distribution of crushed products at 35th hour, 100th hour, and 120th hour in different crushing layers is shown in Figure 20.
From Figure 15, when the depth of the crushing chamber is $0-308 \mathrm{~mm}$, corresponding to the first to the sixth crushing layer, with the increase of crushing chamber depth, the original compression thickness $\mathrm{cr}$ and the length of closed side $c s$ decrease, the actual compression ratio of granular material $\eta_{\mathrm{a}}$ increases, so the expectation of maximum single-particle compression ratio increases. The results show that, in the first to the sixth crushing layer in Figure 20, the crushed material increases, and the change of material mass fraction is accelerated gradually.

In the parallel zone, corresponding to the seventh to tenth crushing layers, the size parameters of the crushing chamber have little change. In this case, the expectation of particle size is smaller than the feed particle size, and the compression ratio of 
single particle becomes smaller. The crushed material is mainly caused by monolayer crushing, and the change of material mass fraction gradually slows down and tends to be stable.

The theoretical mass fraction below $7 \mathrm{~mm}, 12 \mathrm{~mm}$, and $24 \mathrm{~mm}$ of crushed products at 35th hour, 100th hour, and 120th hour in each crushing layer is shown in Figure 21.

The theoretical mass fraction below $7 \mathrm{~mm}, 12 \mathrm{~mm}$, and $24 \mathrm{~mm}$ of crushed products from the fourth to the eighth crushing layer changes obviously. When the crusher works for 120 hours, the mass fraction of crushed products deteriorated with the deterioration of the size and structure of the crushing chamber.

The concave profile before and after wear and liner wear at 120th hour is shown in Figure 22.

The liner wear increases with the depth of the crushing chamber in the parallel zone, the crushing chamber size and material tend to be stable, so the wear loss changes little with the depth of the crushing chamber. The experimental value is the wear of the PYGB1821 cone crusher after $120 \mathrm{~h}$ operation. Compared with the experimental value, the maximum error of liner wear is less than $12 \%$.

The theoretical throughput at different working times is shown in Figure 23.

According to the original compression thickness $\mathrm{cr}$ and the actual compression ratio $\eta_{\mathrm{a}}$, the volume of the material in the crushing chamber can be obtained, and then the theoretical throughput per hour can be obtained. When the liner is worn and the height of concave is adjusted, from Figure 18(a), the original compression thickness of the upper part of the crushing chamber decreases, so the volume of the crushing chamber decreases, and the theoretical throughput decreases. When the adjustment of concave reaches the maximum, the volume of the crushing chamber and the theoretical throughput increase due to the wear of the liner. In the whole life cycle of the liner, the maximum throughput is $573 \mathrm{t} / \mathrm{h}$, and the minimum throughput is $509.3 \mathrm{t} / \mathrm{h}$.

\section{Conclusion}

(1) According to the general rule of compression and crushing of granular materials, the distribution function of maximum single-particle compression ratio is established. The expectation and variance of maximum single-particle compression ratio are related to the expectation of particle size, actual compression ratio of the granular material, original compression thickness, and size distribution coefficient, respectively. Through mathematical derivation and EDEM simulation calculation, a unified model of maximum single-particle compression ratio is obtained.

(2) Based on the Archard wear model, that is, the liner wear is directly proportional to the normal stress and velocity of a point on the mantle, the liner wear model is established. The velocity at a point on the mantle and the angle between the velocity and the normal stress can be expressed analytically. Based on the stress function in previous studies, the liner wear of the mantle was determined quantitatively. The experimental data of Ansteel Group show that the error is within $12 \%$.

(3) Based on the previous research and the distribution model of crushed products, the change of particle size distribution and liner wear in the whole life cycle of the liner were calculated. The experimental data of Ansteel Group show that the error is within 10\%.

(4) The theoretical throughput of the liner in the whole life cycle is calculated. In the whole life cycle of the liner, the difference between the maximum and the minimum throughput is about $11 \%$.

\section{Nomenclature}

$b$ : $\quad$ Length of the open side, $\mathrm{mm}$

cr: $\quad$ Original compression thickness, $\mathrm{mm}$

$c r_{\text {basic }}$ : Original compression thickness under the basic condition, $\mathrm{mm}$

$\mathrm{cr}_{\mathrm{re}}$ : Relative value of original compression thickness

cs: $\quad$ Length of the closed side, $\mathrm{mm}$

$d$ : $\quad$ Particle size of each component, $\mathrm{mm}$

$d_{i}: \quad$ Feed particle size, $\mathrm{mm}$

$d_{o}: \quad$ Crushed particle size, $\mathrm{mm}$

$D_{\text {act }}$ Actual variance of maximum single-particle compression ratio

$D_{\text {basic: }} \quad$ Variance of maximum single-particle compression ratio under the basic condition

$D_{\text {cp }}: \quad$ Variance of crushed particle size, $\mathrm{mm}^{2}$

$D_{d}: \quad$ Variance of particle size, $\mathrm{mm}^{2}$

$D_{d \text {, basic }}$ Variance of particle size under the basic condition, $\mathrm{mm}^{2}$

$D_{\mathrm{m}}: \quad$ Mantle diameter, $\mathrm{mm}$

$D_{\text {m,basic }}$ : Mantle diameter under the basic condition, $\mathrm{mm}$

$D_{\text {part }}$ : Variance of maximum single-particle compression ratio of particles with a specific size

$D_{\text {re: }} \quad$ Relative value of variance of maximum single-particle compression ratio

E: $\quad$ Elastic modulus, Mpa

$E_{\text {act }}$ : Actual expectation of maximum single-particle compression ratio

$E_{\text {basic }}: \quad$ Expectation of maximum single-particle compression ratio under the basic condition

$E_{\mathrm{cp}}$ : $\quad$ Expectation of crushed particle size, $\mathrm{mm}$

$E_{d}$ : $\quad$ Expectation of particle size, $\mathrm{mm}$

$E_{d \text {, basic }}$ Expectation of particle size under the basic condition, $\mathrm{mm}$

$E_{d, \text { re: }}$ Relative value of expectation of particle size, $\mathrm{mm}$

$E_{\text {part }}$ : Expectation of maximum single-particle compression ratio of particles with a specific size

$E_{\mathrm{re}}$ : Relative value of expectation of single-particle compression ratio

$h$ : $\quad$ Material height, $\mathrm{mm}$

$h_{\text {basic: }}$ Material height under the basic condition, $\mathrm{mm}$

$H$ : $\quad$ Brinell hardness

$K$ : Wear coefficient, $\mathrm{mm}^{2} / \mathrm{N}$

$n: \quad$ Rotational speed, rpm

$n_{\text {basic }}$ : Rotational speed under the basic condition, rpm

$N$ : $\quad$ Normal force acting on single particle, $\mathrm{N}$ 
$R_{m}: \quad$ Mantle radius, $\mathrm{mm}$

$R_{O}$ : $\quad$ Distance between a point on the mantle and the suspension point, $\mathrm{mm}$

$R_{p}: \quad$ Single-particle radius, $\mathrm{mm}$

$p: \quad \quad$ Normal stress of a point on the mantle, $\mathrm{MPa}$

$p_{\text {basic }}$ : Normal stress of a point on the mantle under the basic condition, $\mathrm{MPa}$

$s: \quad$ Stroke, $\mathrm{mm}$

$t$ : Working time, $\mathrm{s}$

$T: \quad$ Swing period of the mantle, $s$

$v$ : Velocity of a point on the mantle, $\mathrm{mm} / \mathrm{s}$

$\alpha, \beta$ : Parameters of the beta distribution

$\Delta h: \quad$ Liner wear of a point on the mantle, $\mathrm{mm}$

$\Delta R_{p}: \quad$ Deformation of single-particle radius, $\mathrm{mm}$

$\eta_{a}: \quad$ Actual compression ratio of the granular material

$\eta_{c}$ : Critical compression ratio of single-particle crushing

$\eta_{s}: \quad$ Single-particle compression ratio

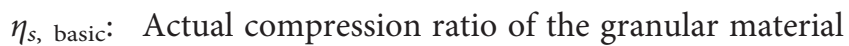
under the basic condition

$v: \quad$ Poisson's ratio

$\varphi_{p}: \quad$ Precession angle of the mantle,

$\sigma_{d}: \quad$ Size distribution coefficient

$\omega$ : Angular velocity of the mantle, $\mathrm{rad} / \mathrm{s}$.

\section{Data Availability}

The experiment is carried out on a PYGB1821 cone crusher. Closed set setting is $19 \mathrm{~mm}$. Rotational speed is $300 \mathrm{rpm}$. The feed particle size distribution is obtained by using the RX-29-10 sieve shaker from W.S. Tyler. The experimental data can be obtained by sending an e-mail to b20160239@ xs.ustb.edu.cn.

\section{Conflicts of Interest}

The authors declare that there are no conflicts of interest regarding the publication of this paper.

\section{Acknowledgments}

This work was supported by the National Key Research and Development Program of China (no. 2016YFC0600805).

\section{References}

[1] E. Lee and M. Evertsson, "Implementation of optimized compressive crushing in full scale experiments," Minerals Engineering, vol. 43-44, no. 1, pp. 135-147, 2013.

[2] K. T. Atta, A. Johansson, and T. Gustafsson, "Control oriented modeling of flow and size distribution in cone crushers," Minerals Engineering, vol. 56, no. 1, pp. 81-90, 2014.

[3] P. Itävuo, M. Vilkko, A. Jaatinen et al., "Dynamic modeling and simulation of cone crushing circuits," Minerals Engineering, vol. 43/44, no. 1, pp. 29-35, 2013.

[4] G. Asbjörnsson, E. Hulthén, and M. Evertsson, "Modelling and simulation of dynamic crushing plant behavior with MATLAB/Simulink," Minerals Engineering, vol. 43-44, pp. 112-120, 2013.
[5] K. Holmberg, P. Kivikytö-Reponen, P. Härkisaari, K. Valtonen, and A. Erdemir, "Global energy consumption due to friction and wear in the mining industry," Tribology International, vol. 115, pp. 116-139, 2017.

[6] M. Lindqvist and C. M. Evertsson, "Development of wear model for cone crushers," Wear, vol. 261, no. 3-4, pp. 435-442, 2006.

[7] J. Franke, P. W. Cleary, and M. D. Sinnott, "How to account for operating condition variability when predicting liner operating life with DEM - a case study," Minerals Engineering, vol. 73, pp. 53-68, 2015.

[8] S. Ala-Kleme, P. Kivikyto-Reponen, J. Liimatainen et al., "Abrasive wear properties of tool steel matrix composites in rubber wheel abrasion test and laboratory cone crusher experiments," Wear, vol. 263, no. 1-6, pp. 180-187, 2007.

[9] D. Li, Y. Wang, C. Wang, and S. Li, "Research on the wear behavior of the fixed cone liner of a cone crusher based on the discrete element method," ACS OMEGA, vol. 5, no. 19, pp. 11186-11195, 2020.

[10] Z. S. Wang, R. J. Wang, Q. O. Fei et al., "Structure and microscopic wear analysis of lining material based on EDEM," in Proceedings of the International Conference on Electronic Information Technology and Computer Engineering (EITCE), Shangha, China, September 2017.

[11] G. W. Delaney, R. D. Morrison, M. D. Sinnott, S. Cummins, and P. W. Cleary, "DEM modelling of non-spherical particle breakage and flow in an industrial scale cone crusher," Minerals Engineering, vol. 74, pp. 112-122, 2015.

[12] F. P. André and L. M. Tavares, "Simulating a laboratory-scale cone crusher in DEM using polyhedral particles," Powder Technology, vol. 372, no. 15, pp. 362-371, 2020.

[13] P. W. Cleary and M. D. Sinnott, "Simulation of particle flows and breakage in crushers using DEM: Part 1 - compression crushers," Minerals Engineering, vol. 74, pp. 178-197, 2015.

[14] Z. He, "Piston skirt friction loss and dynamic analyses based on FEM method," Industrial Lubrication and Tribology, vol. 70, no. 4, pp. 656-672, 2018.

[15] H. Bakowski, "Wear mechanism of spheroidal cast iron piston ring-aluminum matrix composite cylinder liner contact," Archives of Metallurgy and Materials, vol. 63, no. 1, pp. 481-490, 2018.

[16] Y.-Z. Xing, Z. Liu, G. Wang et al., "Improvement of interfacial bonding between plasma-sprayed cast iron splat and aluminum substrate through preheating substrate," Surface and Coatings Technology, vol. 316, pp. 190-198, 2017.

[17] Y. Chen and F. Meng, "Numerical study on wear evolution and mechanical behavior of steel wires based on semi-analytical method," International Journal of Mechanical Sciences, vol. 148, pp. 684-697, 2018.

[18] Y. Chen, H. Tan, and W. Qin, "Semi-analytical analysis of the interwire multi-state contact behavior of a three-layered wire rope strand," International Journal of Solids and Structures, vol. 202, pp. 136-152, 2020.

[19] V. V. Aleshin and A. Papangelo, "Friction-induced energy losses in mechanical contacts subject to random vibrations," International Journal of Solids and Structures, vol. 190, pp. 148-155, 2020.

[20] G. G. Li, B. Q. Shi, and R. Y. Liu, "Dynamic modeling and analysis of a novel 6-DOF robotic crusher based on movement characteristics," Mathematical Problems in Engineering, vol. 2019, Article ID 2847029, , 2019.

[21] T. W. Liu, J. D. He, and W. J. Xu, "Energy properties of failure of marble samples under triaxial compression," Journal of 
Geotechnical and Geoenvironmental Engineering, vol. 35, no. 02, pp. 395-400, 2013.

[22] H. P. Xie, R. D. Peng, and Y. Ju, "Energy dissipation of rock deformation and fracture," Chinese Journal of Rock Mechanics and Engineering, vol. 21, pp. 3565-3570, 2004.

[23] Y. Ma, X. Fan, Q. C. He et al., "Mathematical modeling of particle size and particle shape of crushing quality for cone crusher," Journal of Mechanical Engineering, vol. 49, no. 06, pp. 95-102, 2013.

[24] X. Wang, "Research on optimization of crushing performance of cone crusher based on laminated crushing theory," Master's thesis, Yanshan University, Qinhuangdao, China, 2017.

[25] J. Quist and C. M. Evertsson, "Cone crusher modelling and simulation using DEM," Minerals Engineering, vol. 85, pp. 92-105, 2015.

[26] M. Johansson, J. Quist, E. Hulthén, and M. Evertsson, "Cone crusher performance evaluation using DEM simulations and laboratory experiments for model validation," Minerals Engineering, vol. 103-104, pp. 93-101, 2017.

[27] P. W. Cleary, M. D. Sinnott, R. D. Morrison, S. Cummins, and G. W. Delaney, "Analysis of cone crusher performance with changes in material properties and operating conditions using DEM," Minerals Engineering, vol. 100, pp. 49-70, 2017.

[28] G. C. Duan, B. Q. Shi, Y. H. Shen et al., "Establishment of a laminated crushed products function and numerical analysis," Energies, vol. 12, no. 5, Article ID 819, 2019.

[29] C. M. Evertsson and M. Lindqvist, "Power draw in cone crushers," in Proceedings of the Presentation at the Minerals Engineering Conference, Perth, Australia, September 2002.

[30] B. L. Fan, "Study on mechanism of the cone crusher based on discrete element," M. Sc. thesis, University of Science and Technology Beijing, Beijing, China, 2016.

[31] J. F. Archard, "Contact and rubbing of flat surfaces," Journal of Applied Physics, vol. 24, no. 8, pp. 981-988, 1953.

[32] G. C. Duan, B. Q. Shi, and J. Gu, "Establishment of energy consumption model and multi-objective optimal control method of 6-DOF robotic crusher," Advances in Mechanical Engineering, vol. 12, no. 10, 2020.

[33] W. Y. Zhang, "The design and failure analysis of cone crusher's moving liner," M. Sc. thesis, University of Science and Technology Beijing, Beijing, China, 2015.

[34] T. Brosh, H. Kalman, and A. Levy, "Fragments spawning and interaction models for DEM breakage simulation," Granular Matter, vol. 13, no. 6, pp. 765-776, 2011. 